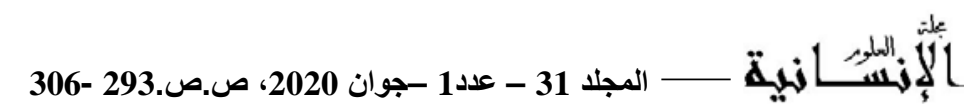

\title{
العقوبات الإقتصادية في السياسة الخارجية الأمريكية
}

\section{Economic sanctions in American foreign policy}

تاريخ الاستلام :2019/10/26؛ تاريخ القبول : 2020/02/23

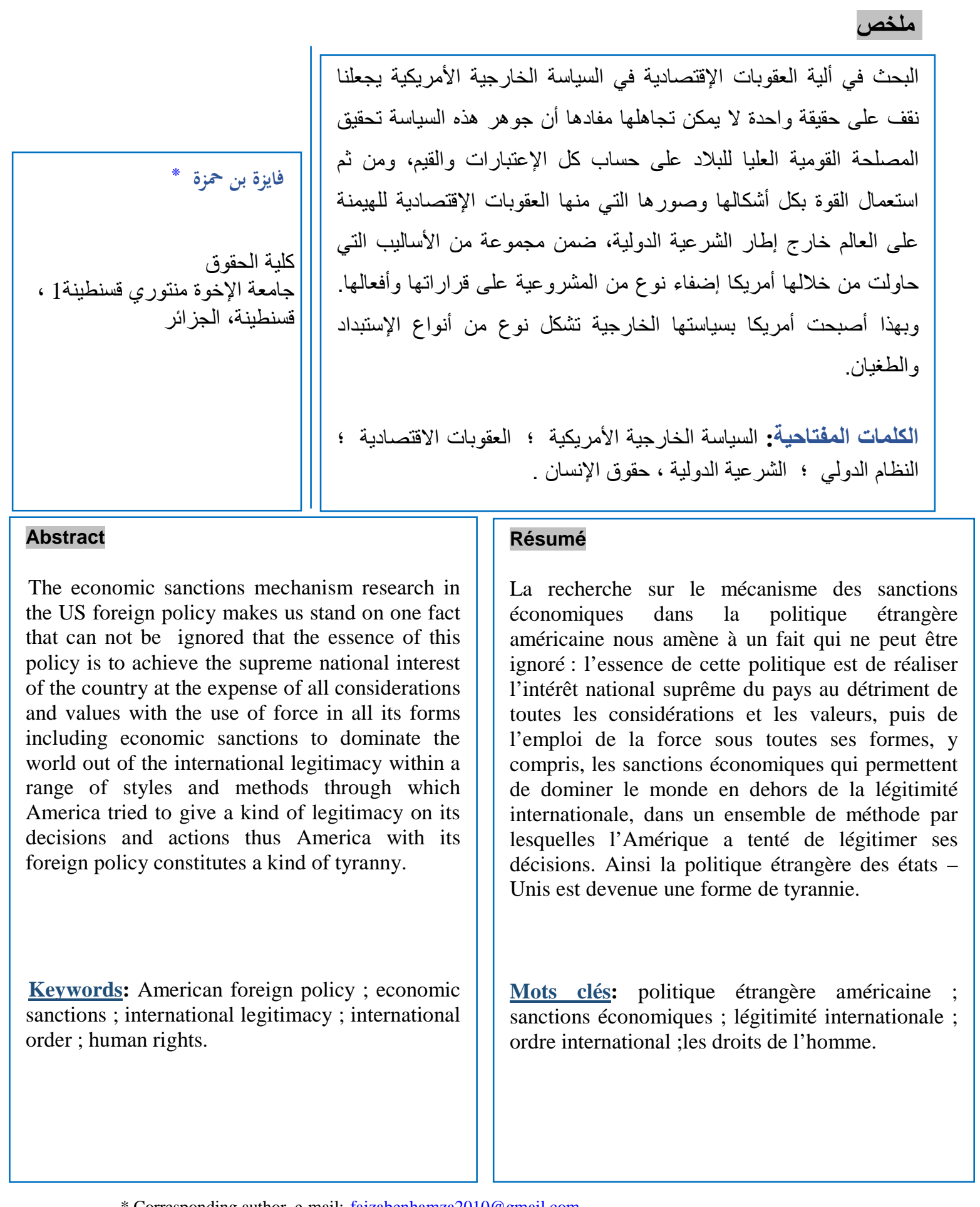

* Corresponding author, e-mail: faizabenhamza2010@gmail.com 


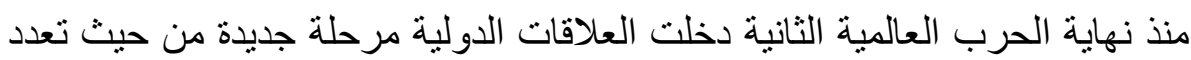

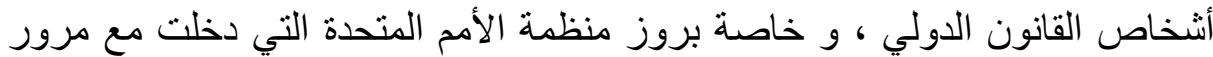

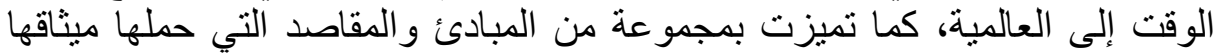

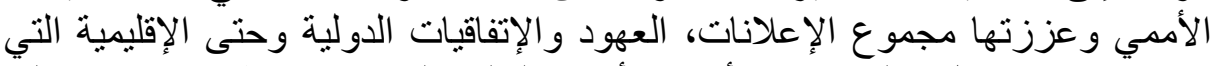

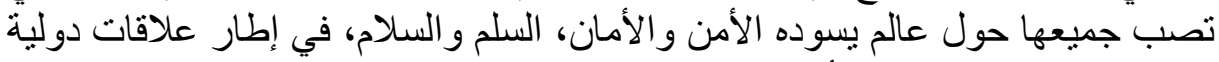

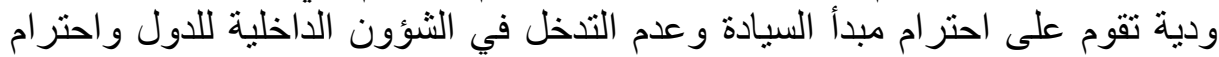

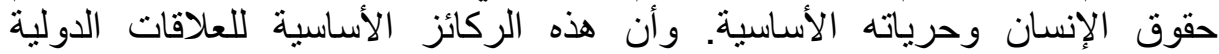

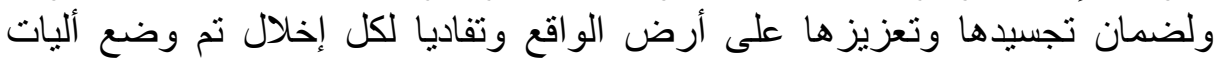
وتدابير احتر ازية لمجابهة أي إخلال في إطار دائما تجسيد والفاديا واحتر ام مقاصد ومبادئ

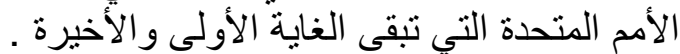

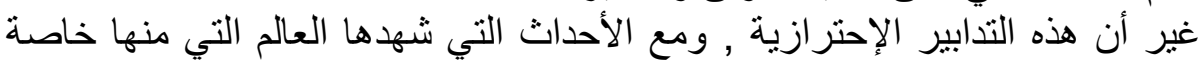

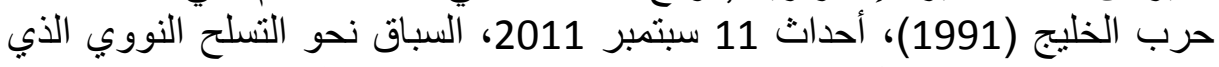

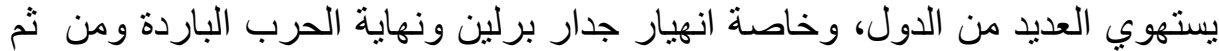

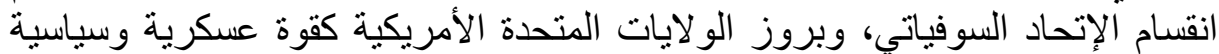

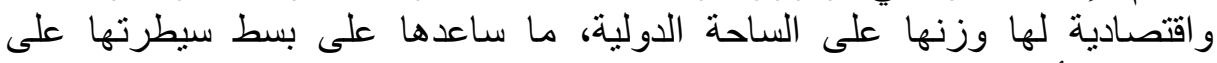
المنظمة الأممية ومن ثم على العالم من خلال توجيه سياستها الخارجية إلى نحو خدمة

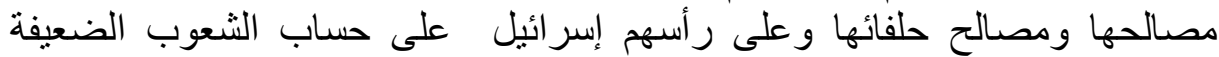

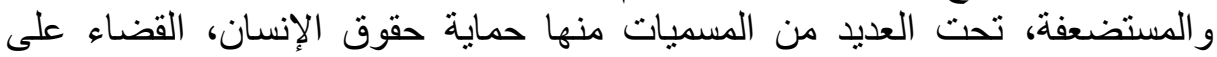

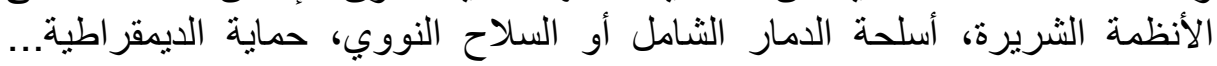
و و غير ها.

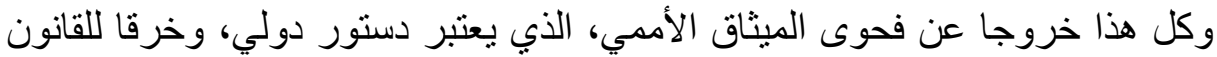

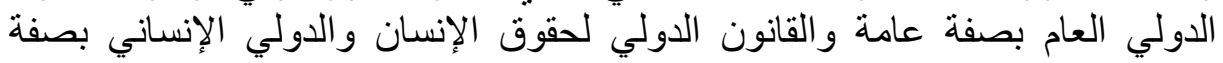

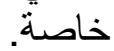

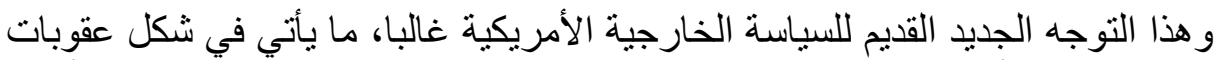

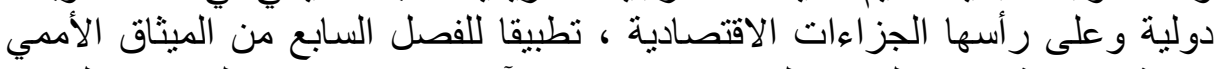

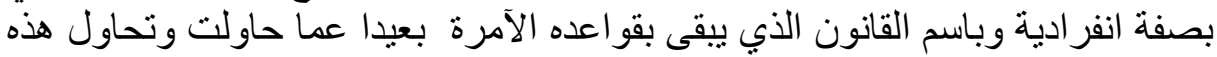

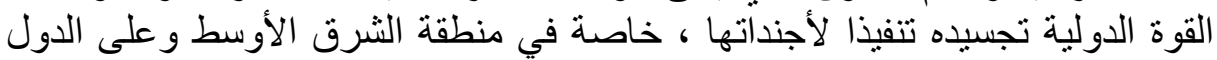
العربية والإسلامية على الخصوص في إطار مأ بسمى بسياسة الكيل بمكيالين ومبدأ الانتقائية. وتبقى الجزاءات الدولية الاقتصادية، كآلية من آليات حماية السلم والأمن الدولي

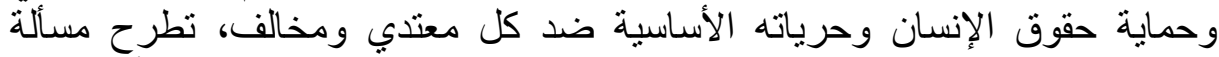

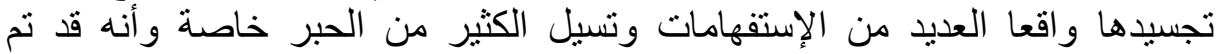

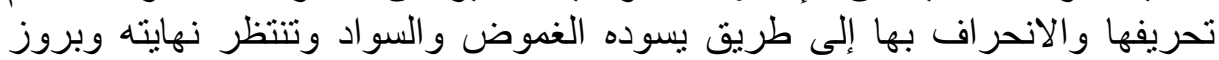

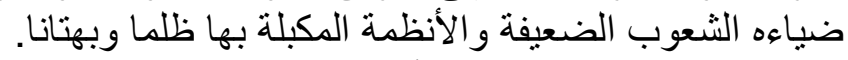

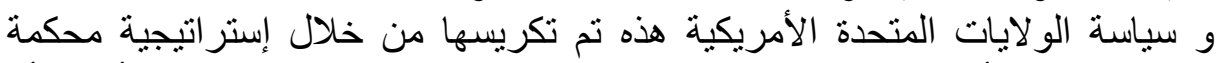

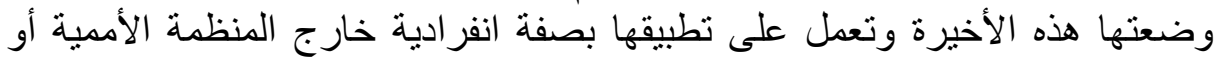

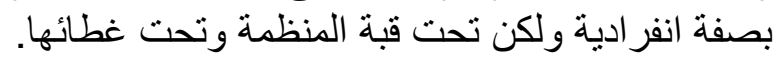

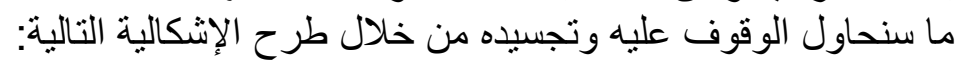

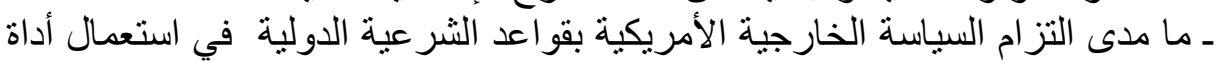

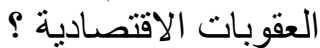

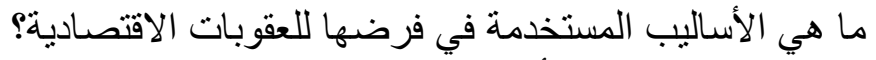

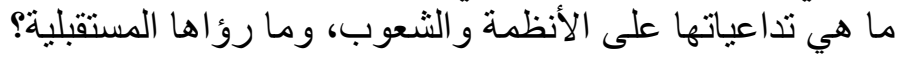


هذه الإشكالية التي حاولنا الإجابة عليها من خلال إتباع المنهجية القائمة على أسلوب

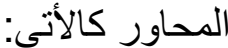
المحور الأول: السياسة الخارجية الأمريكية والثر عية الدولية. أو لا: نظرة على السياسة الخارجية الأمريكية. ثنانيا: موقعها من الثرعية الثية الدولية. ثالثا: تداعياتها على أداة العقوبات الاقتصادية الألية الدولية.

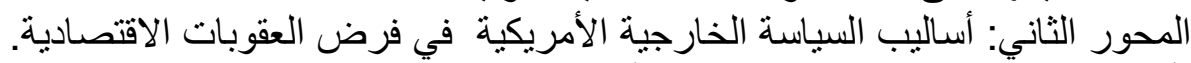

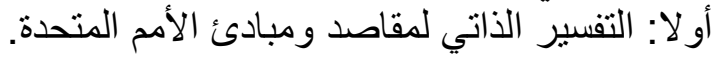

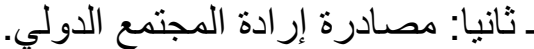
ثالثا: السطو على النّا: النظام الدولي.

المحور الثالث: تداعيات السياسة الخاتية الخارجية الأمريكية بعقوباتها ورؤاها الها المستقبلية.

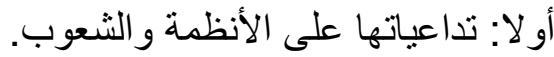

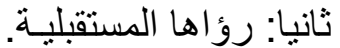

المحور الأول: السباسة الخارجية الأمريكية والثرعية الدولية. ـ أولا: نظرة على السياسة الخارجية الأمريكية. السياسة الخارجية الأمريكية هي حقيقة قوية ومركبة وترجة الأرية جذور ها إلى أكثر من

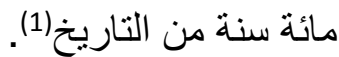
وبهذا، في إطار الحديث عن السياسة الخارجية نقف على أن هذئ هذه الأخيرة تعد ظاهرة

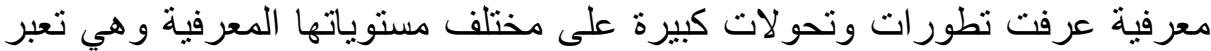

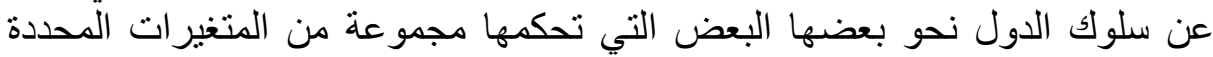

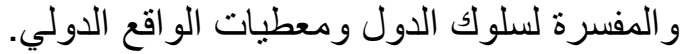

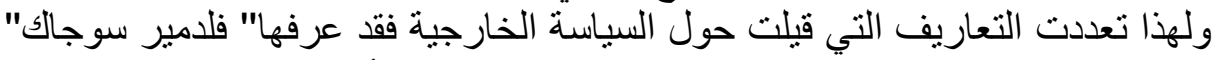

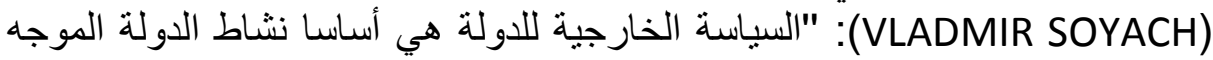

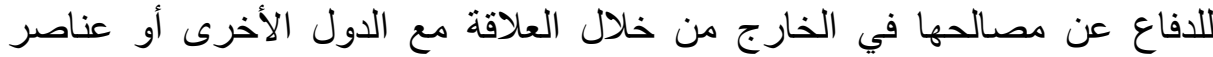

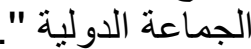

أما كينت تومبسون: "السياسة الخارجية هي النظرة الإيديولوجية و النظرة التحليلية أما

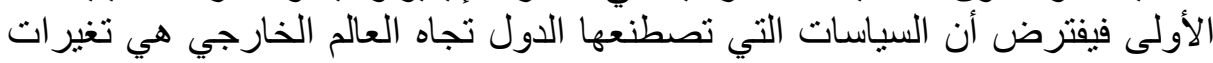

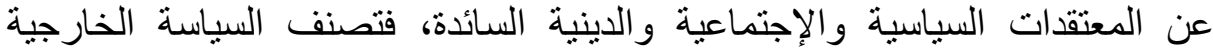

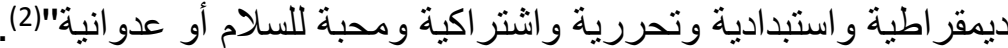

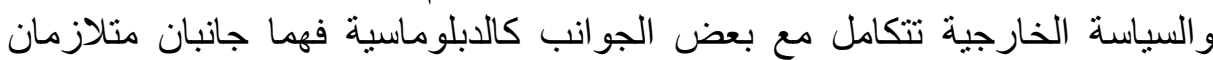

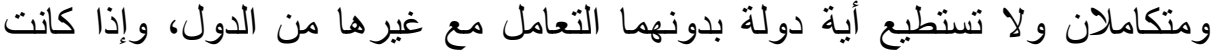
السياسة الخارجية تشكل الخطة المرسومة لتوجيه العلاقات الخارجة التهاتية للدولة، فإنان

الدبلوماسية هي عملية تتفيذ لهذه الخطة. ذللك أن الدول الحديثة تخطط لنفسها خطة بعيدة لفئة وقريبة المدى بما يتفق ومصالحها،

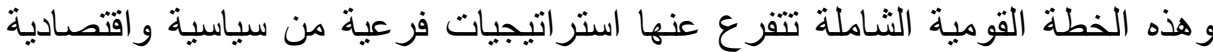

و وعسكرية (3).

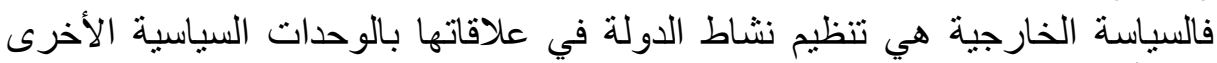

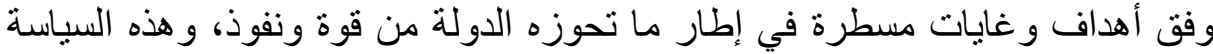
الخارجية تقوم على مجموعة من المحددات النابعة من البيئة الخارجية وكافة وكذا البية البيئة

الاخلية

وفيما يتعلق بتحديد السياسة الخارجية الأمريكية نقف على أن هذه السياسة المؤثرة

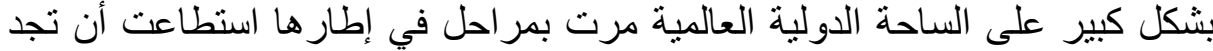

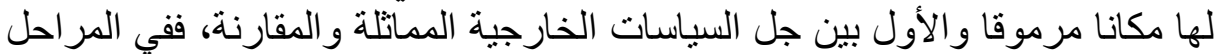




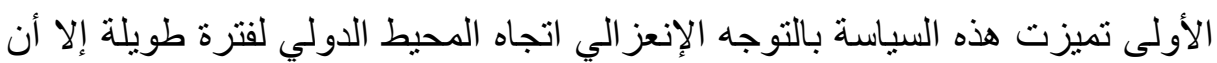

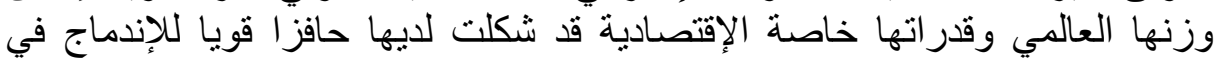

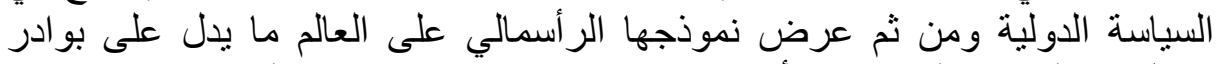

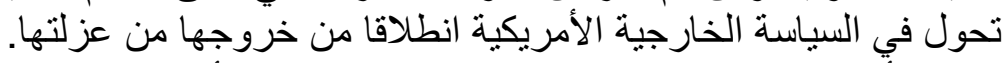

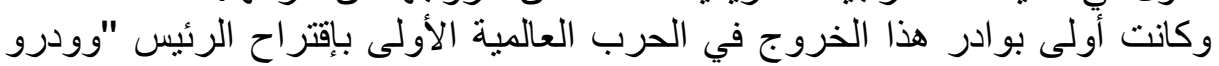

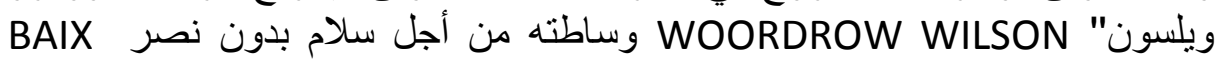
SON VICTOIRE وكان أيضا أحد بو ادر التدخل في الثؤون الأوروبية، ما أدى إلى ظهور مفاهيم جديدة

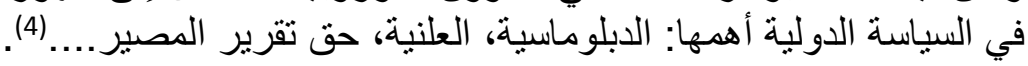

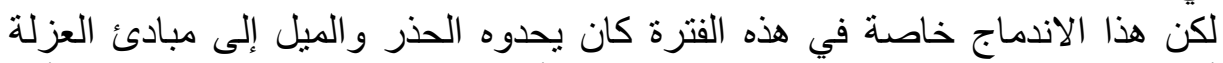

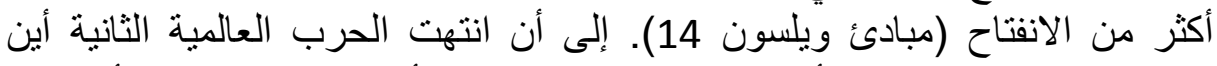

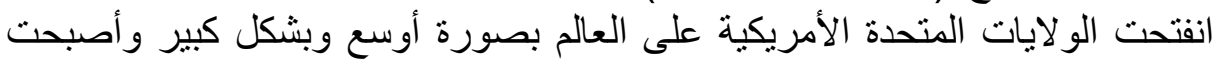

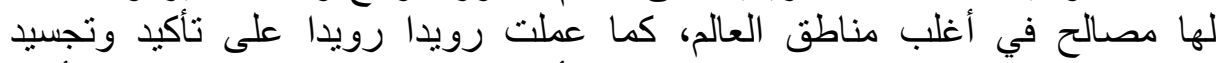

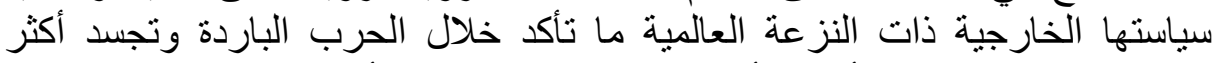

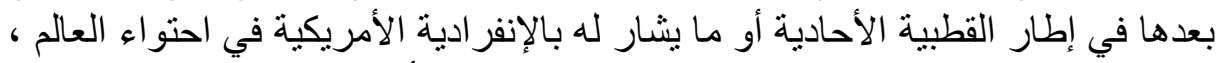

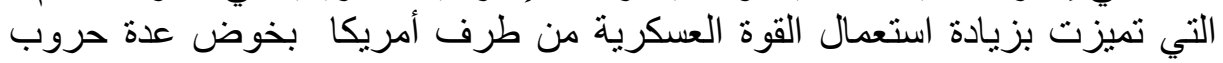

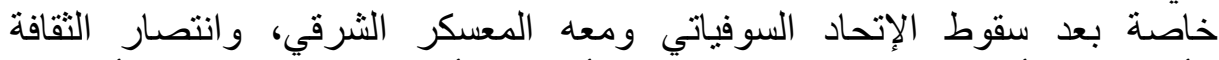

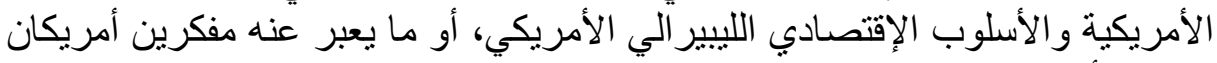

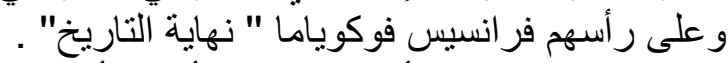

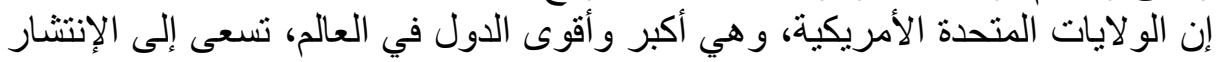

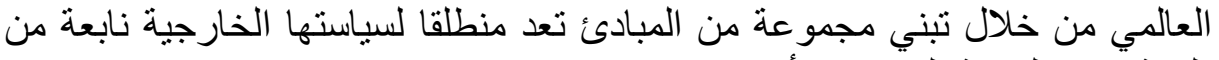

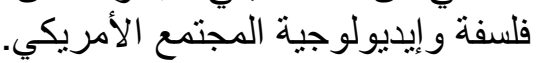
هذه المبادئ الداعمة للسياسة الخارجية الأريكية الأمريكية مستوحاة من دستور فيلادلفيا 1789

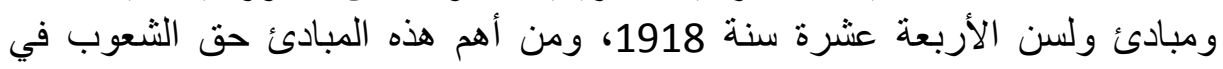

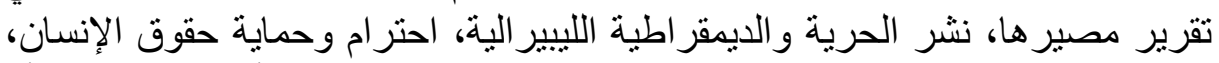

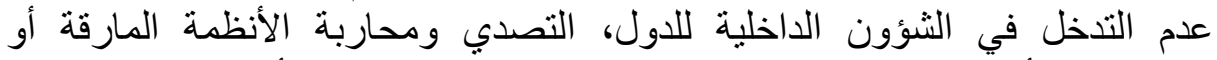

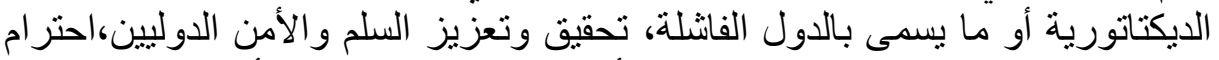

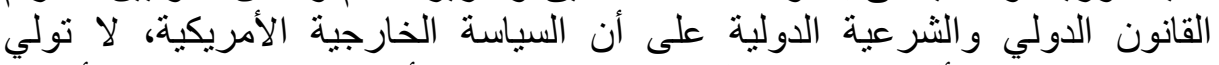

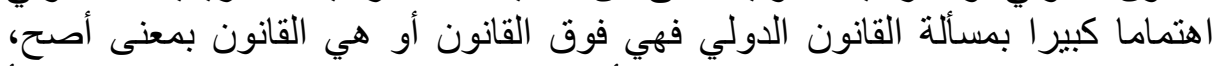

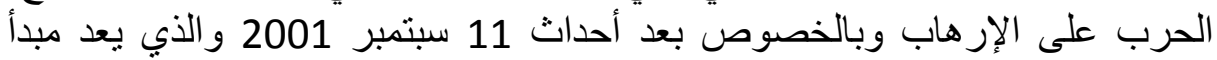

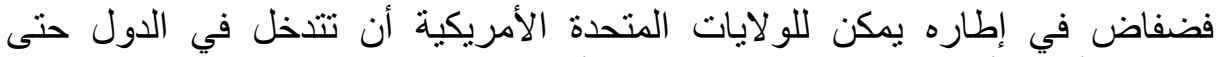

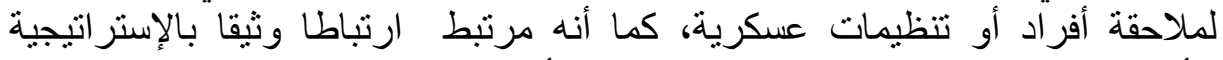

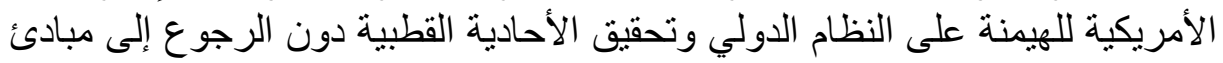
القانون الدولي. و غير ها من ألمبادئ التي حاولت السياسة الخارجية لأمريكا جعلها مبادئ عالمية بما

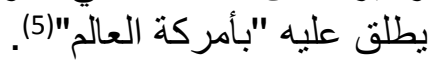

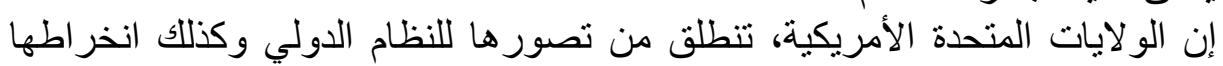

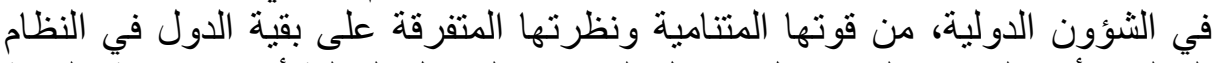

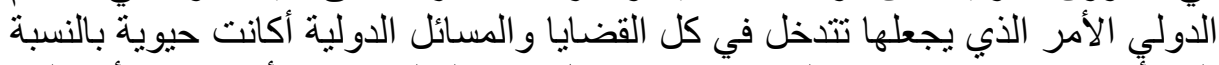

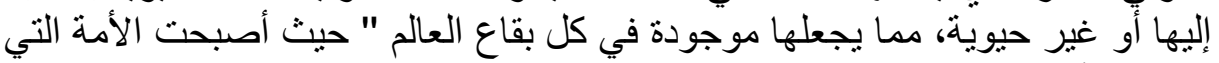

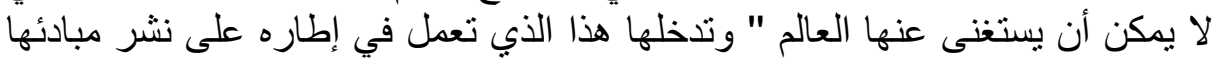

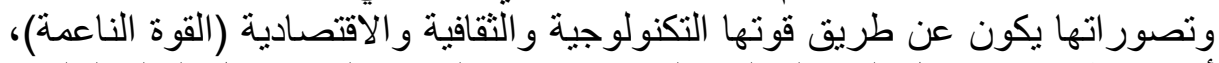
أو عن طريق استعمال القوة الصلبة (العسكرية) ما فعلته وتفعله ولفه مع دول التهادية العالم الثالث. 


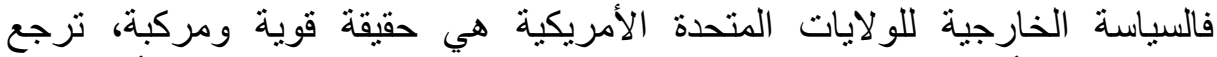

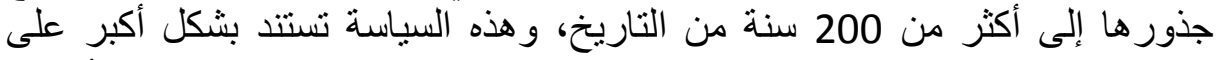

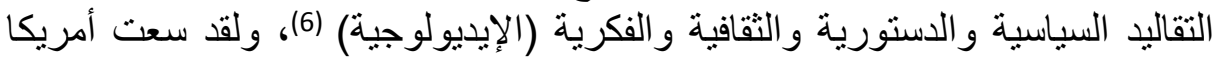

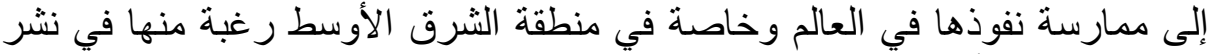

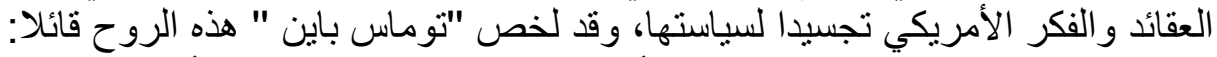

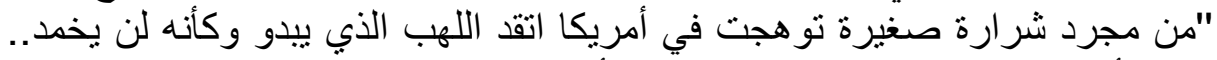

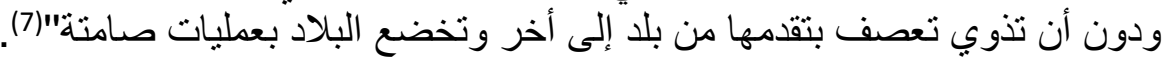

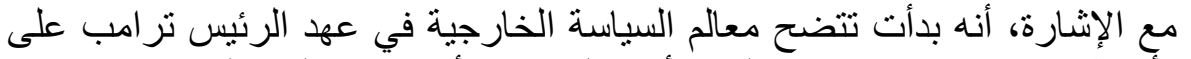

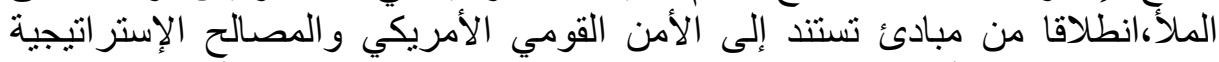

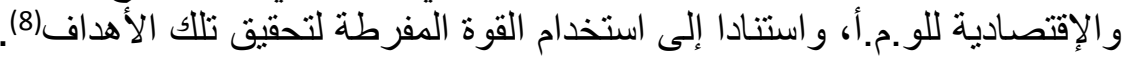

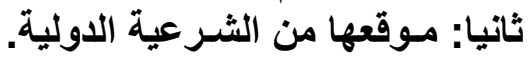

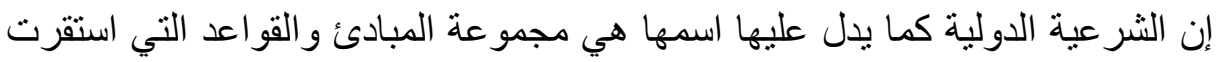

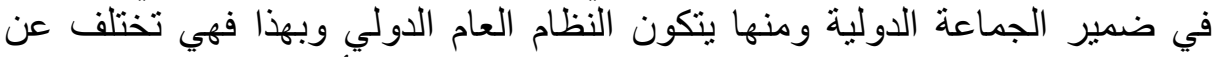

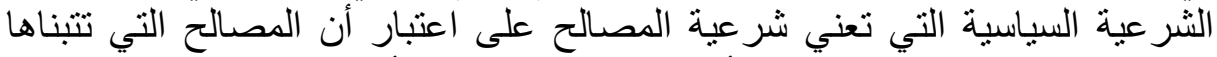

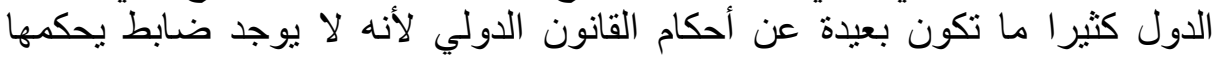

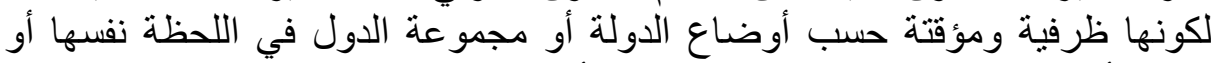
زمنيا بأن تكون اليوم غير تللك التي كانت بالأمس والته والتي التي تكون مستقبلا.

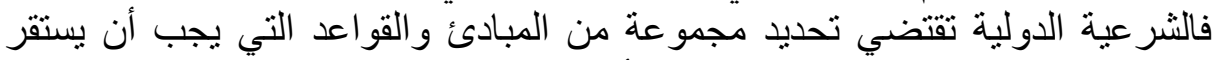

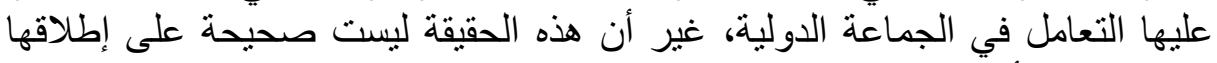

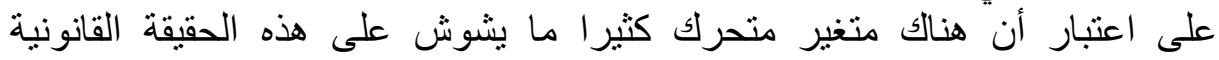

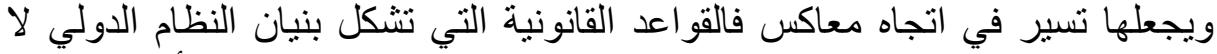

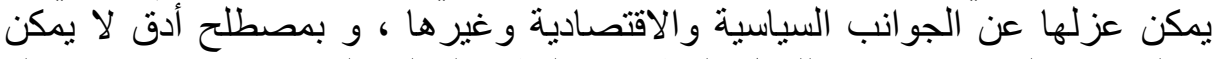

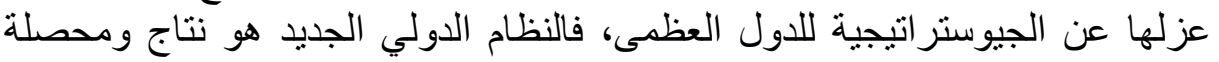

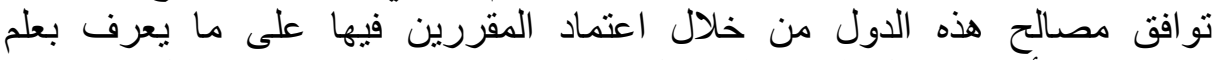

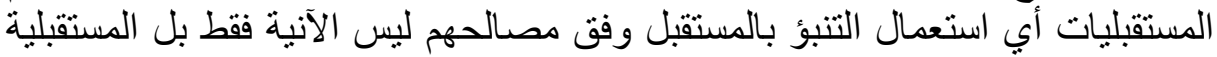
كذللك، لأنهم يعملون على الرفع من درجة حريتهم بتنظيم حاضر هم وفق مستقبلهم

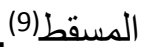

ومن ثم فإذا كانت الثرعية الدولية بمنظور شامل تشمل الجوانب التبانبة القانونية الفنية

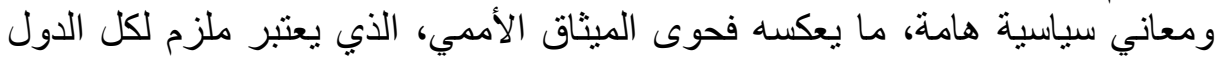

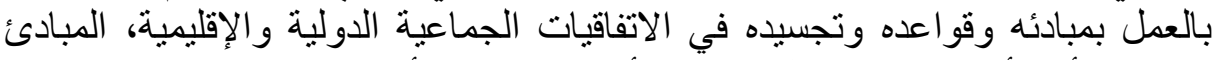

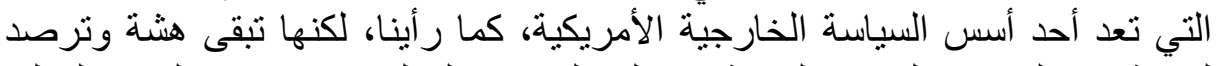

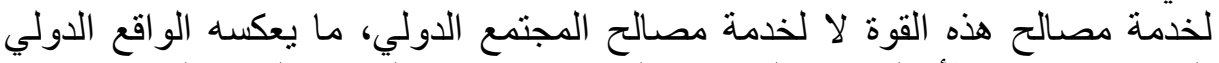

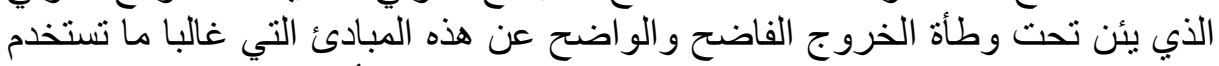

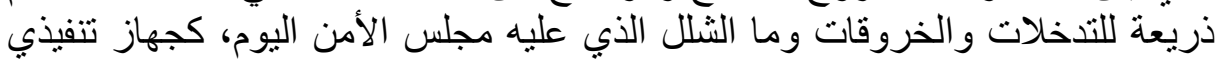

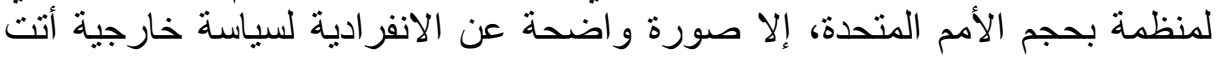
على الأخضر و اليابس. فالدول اليوم أصبحت لا تقوى على معابلى معارضة اقتراحاتها الكثيرة في مجلس الأمن

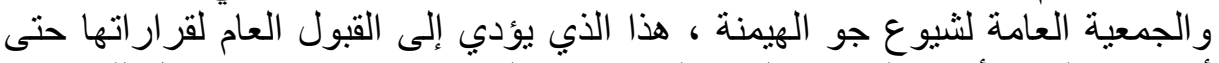

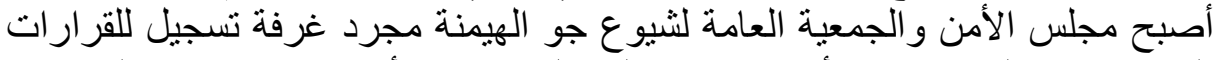

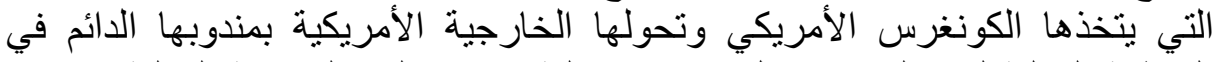

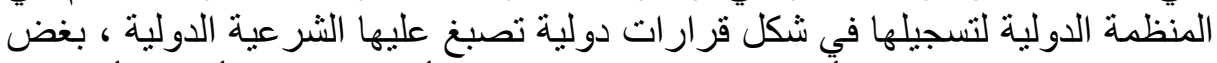

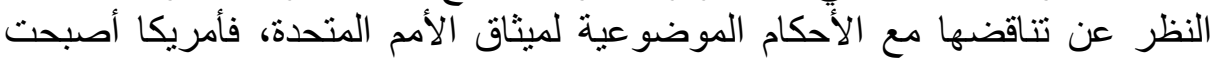

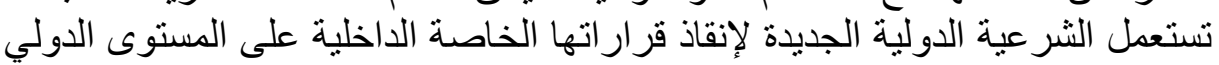

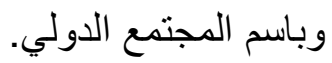


هذه السياسة الظالمة التي تجد من يساندها، فققهاء القانون الدولي المنظرين للسلوك

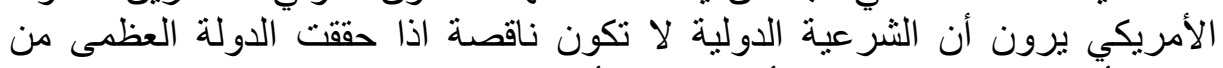

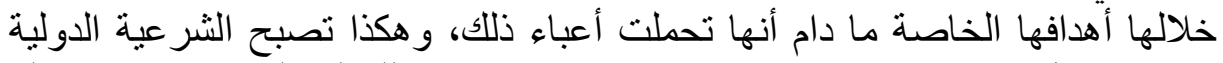

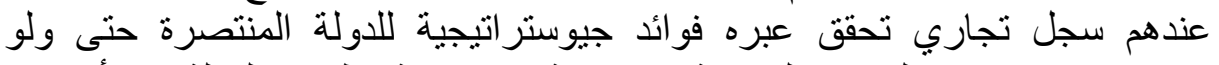

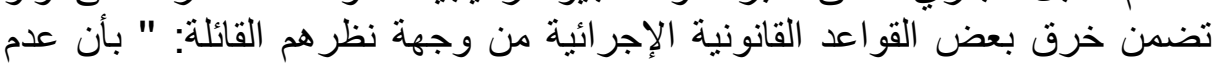

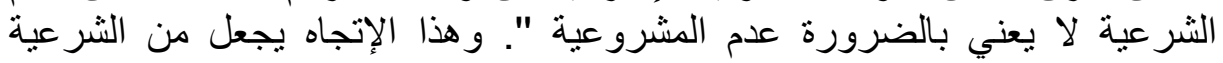

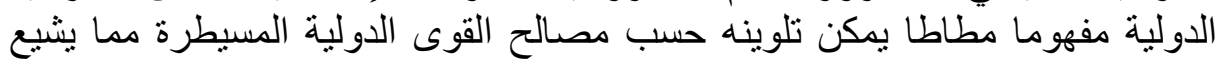

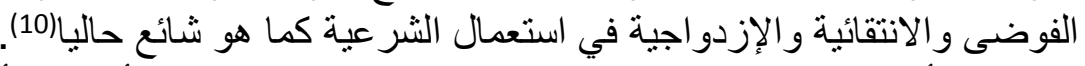

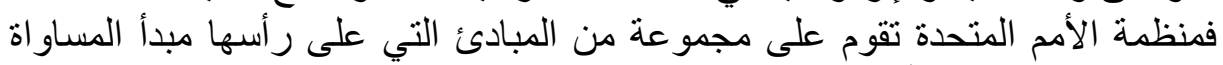

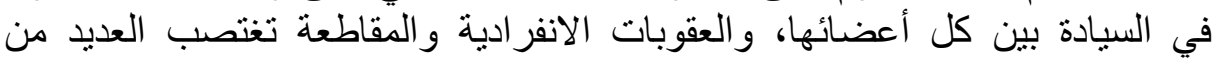

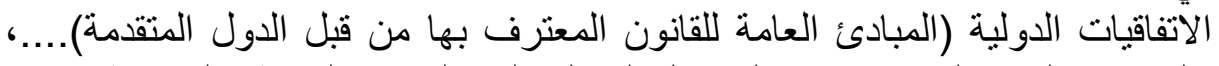

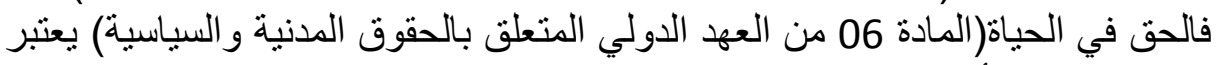

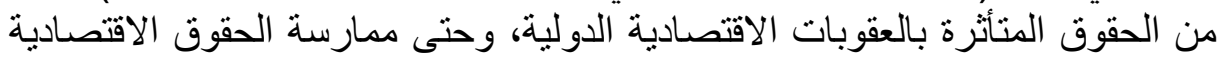

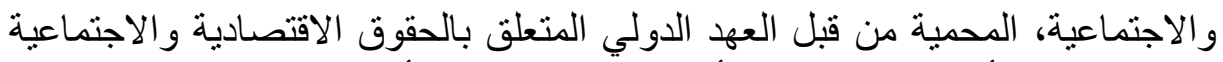

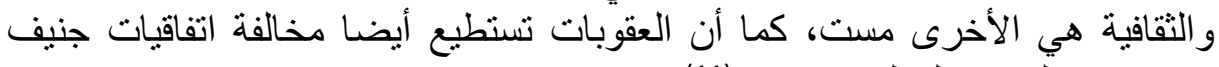
ومعاهدات القانون الدولي الإنساني(11).

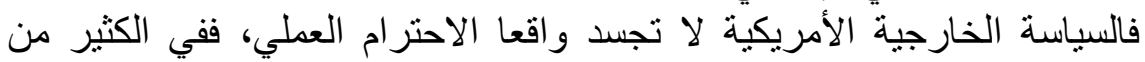

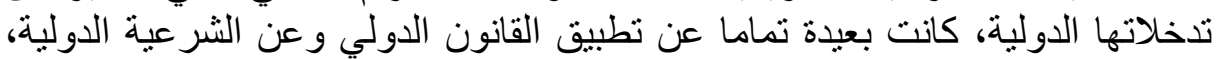

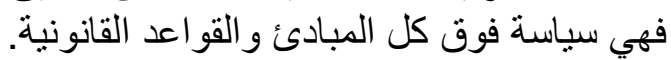

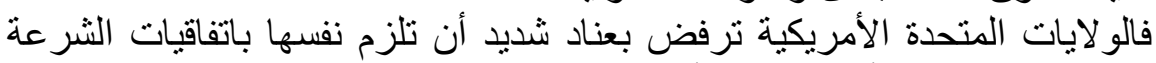

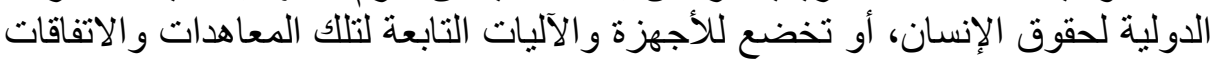

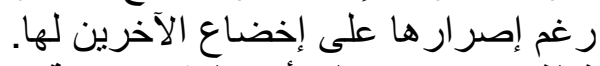

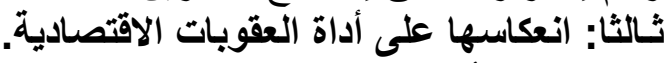

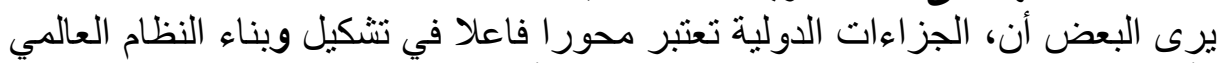

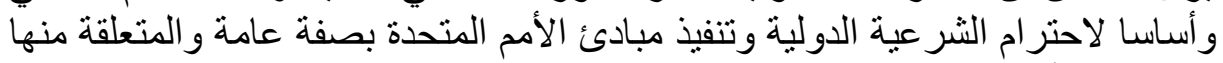

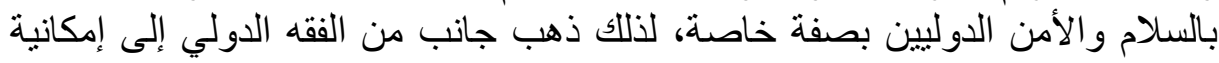

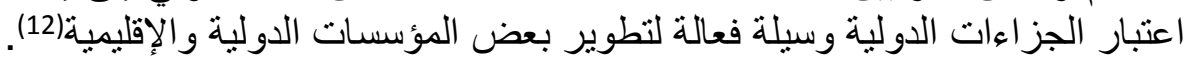

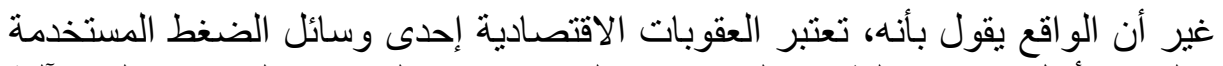

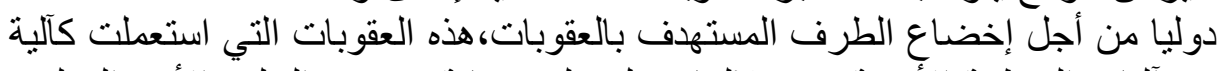

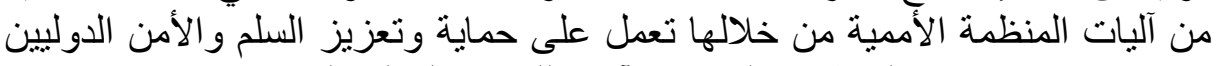

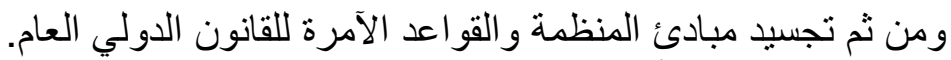

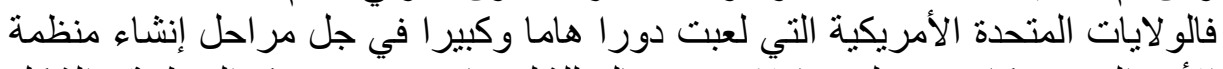

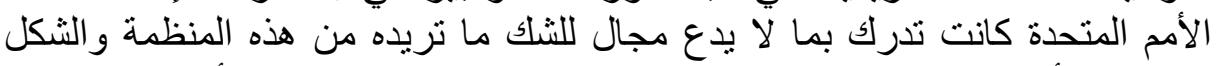

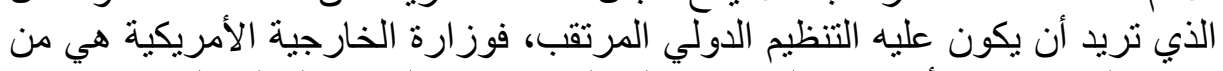

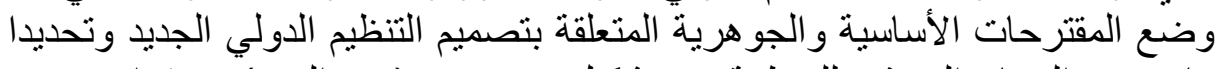

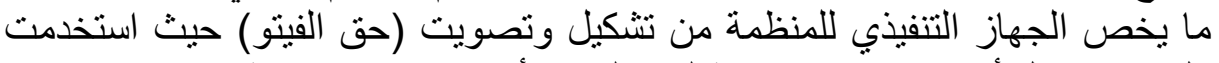

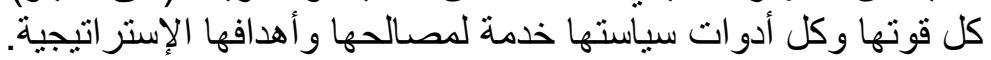

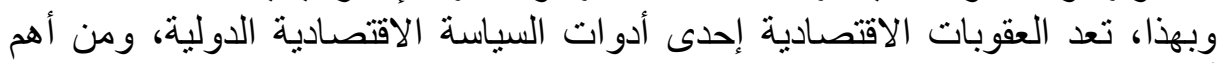

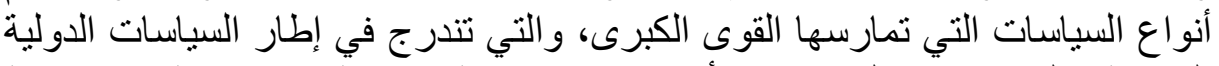

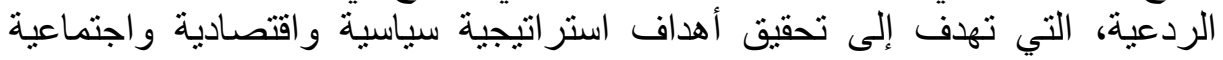
معينة(13).

فالعقوبات الاقتصادية وسيلة من وسائل تحقيق غايات السياسة الخارجية لدولة ما أو الو الوائ لمجموعة من الدول بغرض المحافظة على السلم و الأمن الدوليين. 
فالولايات المتحدة ، اتبعت سياسة خاصة في توقيع العقوبات الاقتصادية حيث

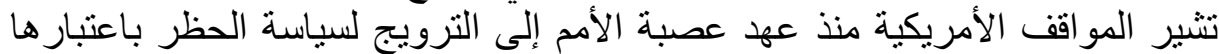

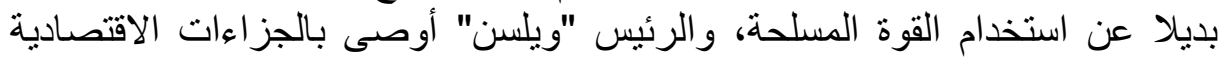

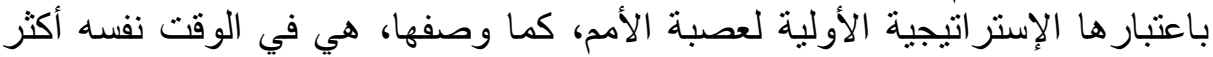
سرعة ونظافة وفعالية من الصر اع في الاعة في ساحة القتال.

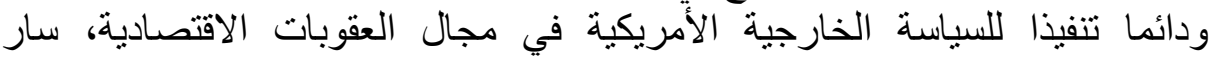

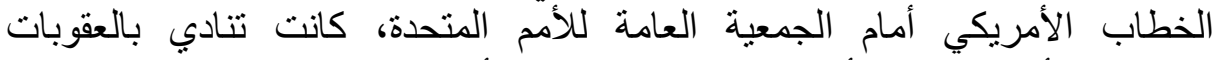

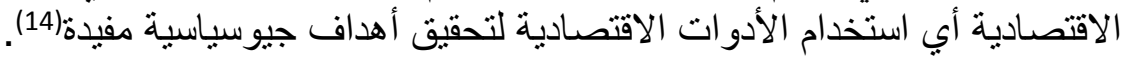

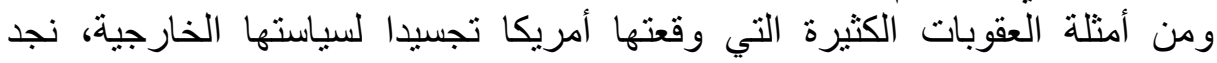

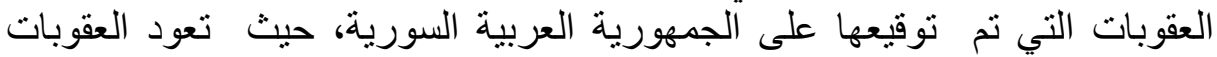

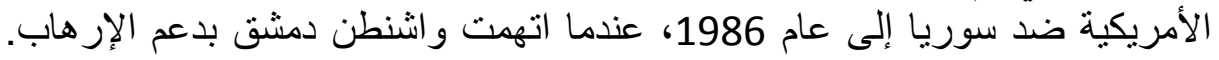

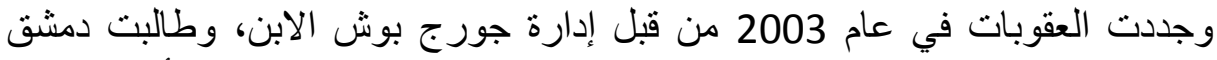

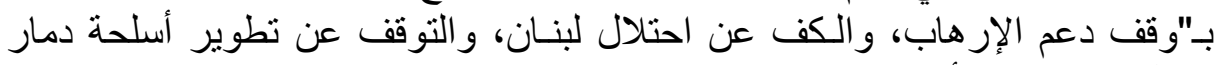

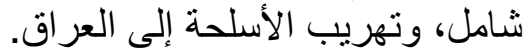

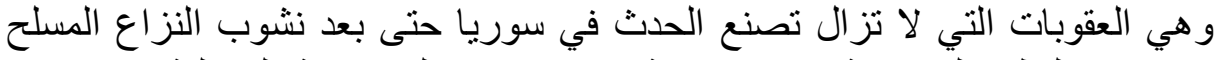

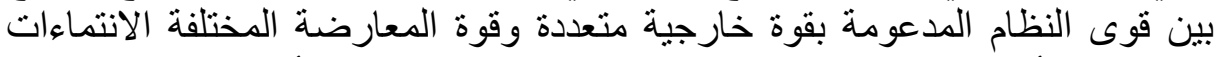

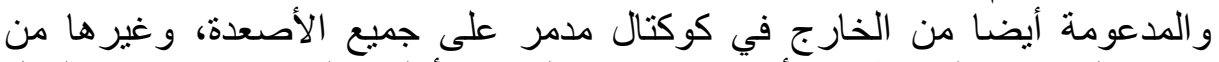

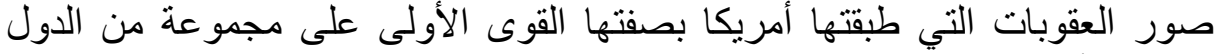

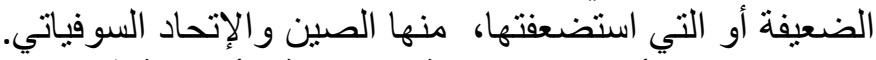

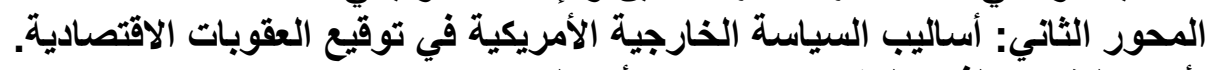

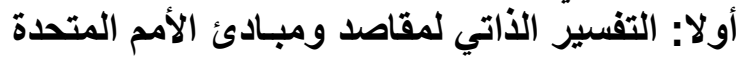

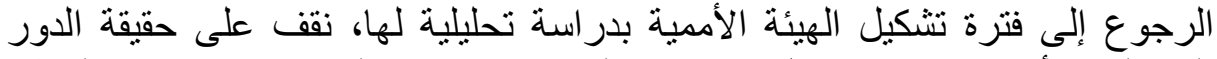

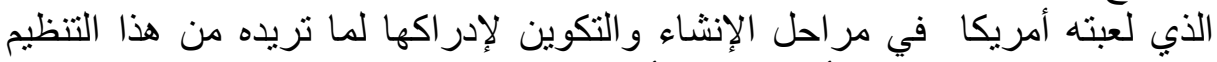

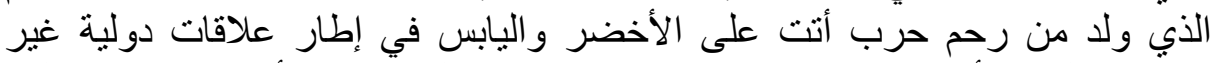

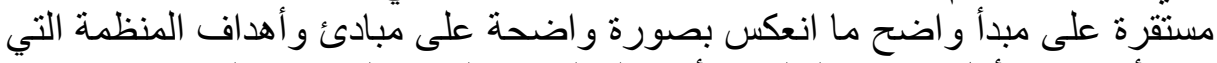

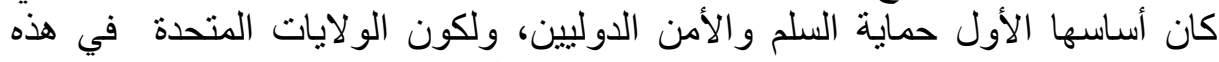

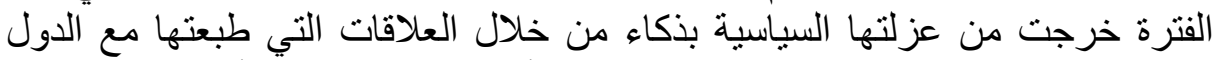

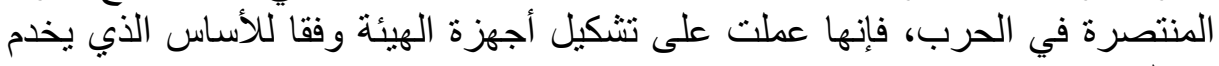

مصلحتها.

فتتكيل الهيئة بمبادئها وأهدافها وحتى هياكلها كان وفقا للرؤية والرغبة الأمريكية

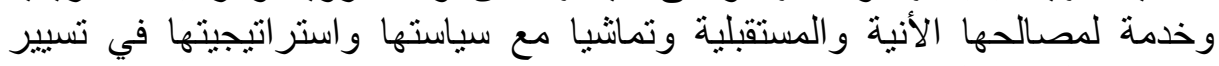

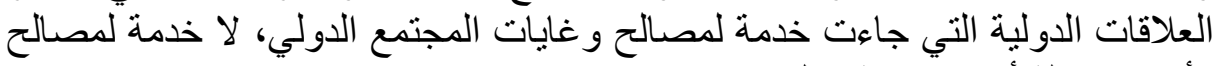

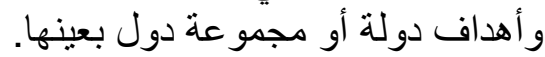

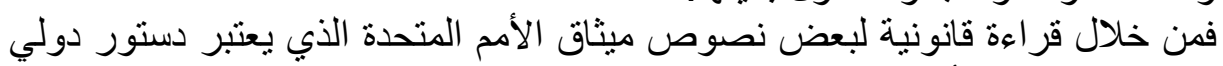

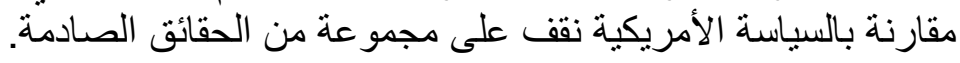

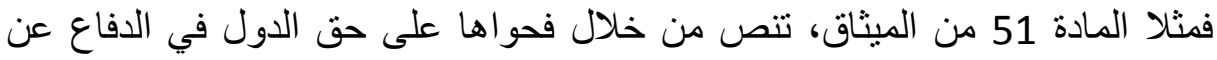

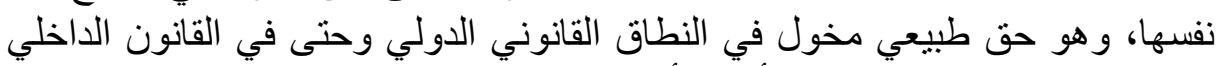

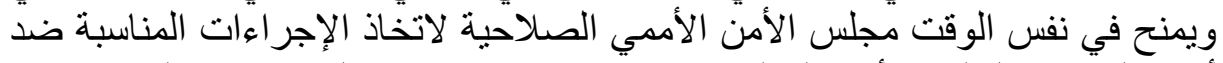

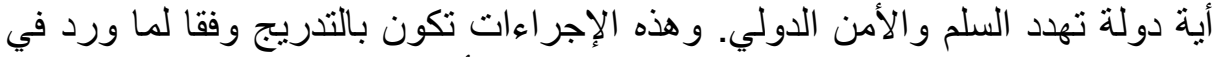

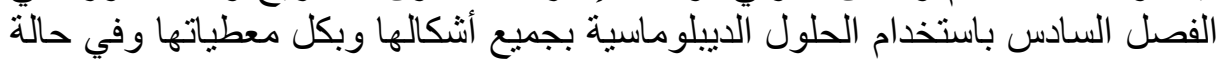

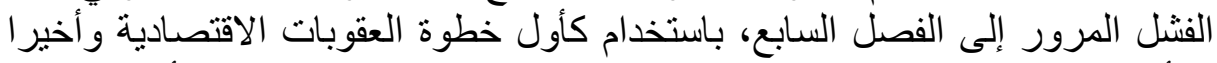

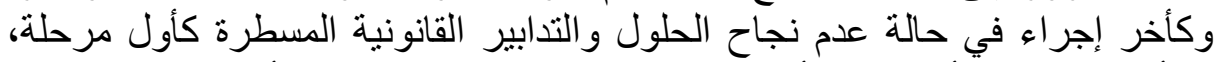
يلجأ إلى المرحلة أو الحل الأخير المجسد في العقوبات العسكرية أو ما بصطلح على العلى 
لكن الولايات المتحدة الأمريكية من خلال سياستها الخارجية دائما توهم العالم أنها تحترم وتستند وتجسد مبادئ، مقاصد وأهداف الأمم المتحدة خدمة للمصلحة العامة

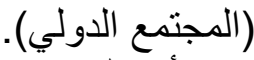
غبير أن الواقع لا لاعكس هذه الحقيقة، فالدولة الأولى على المستوى العالمي تأخذ

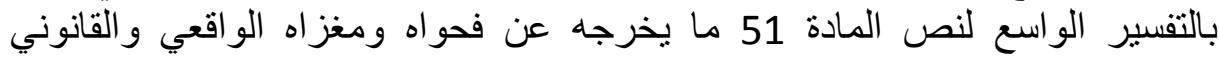

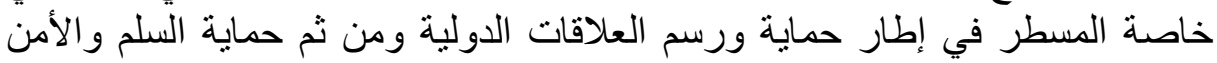

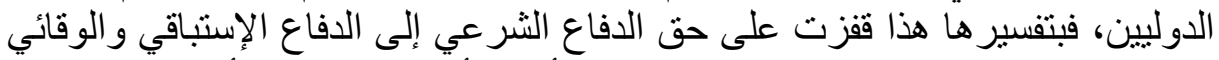

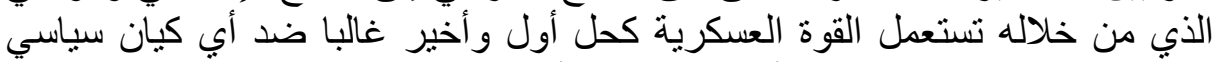

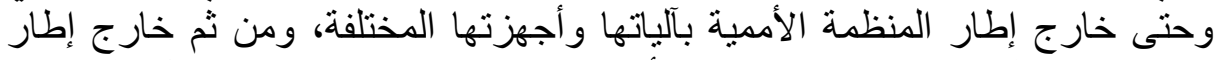

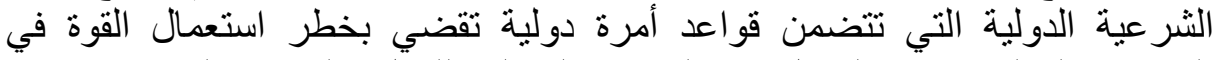

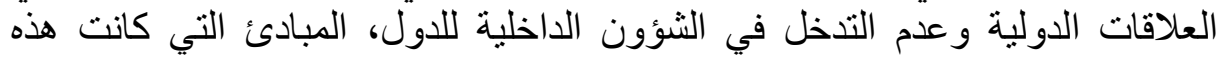

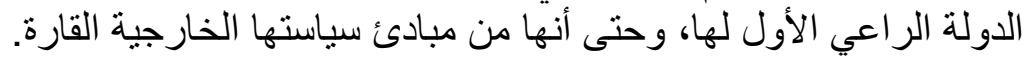

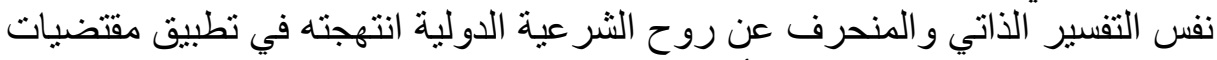

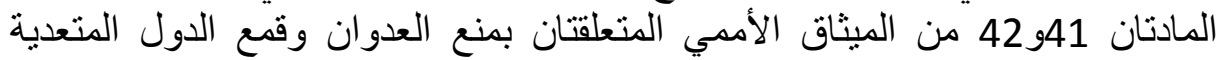

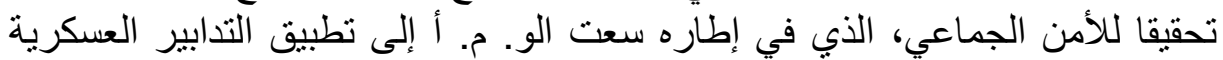

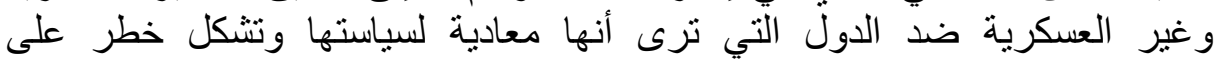

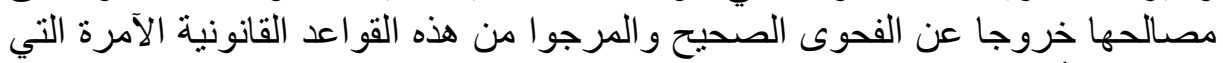
لا مجال لتأويلها و الخروجا عن الفحوى عن فحو الها.

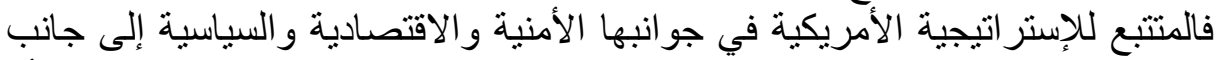

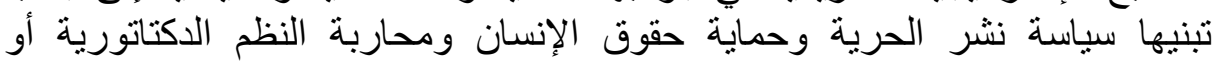

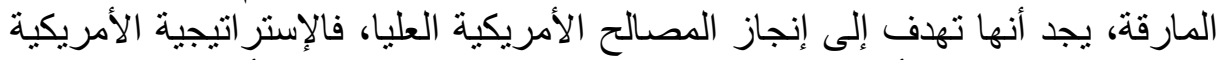

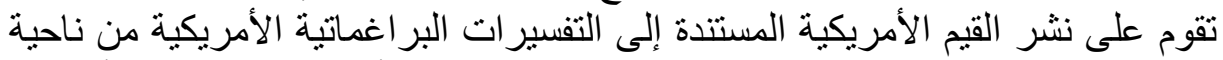

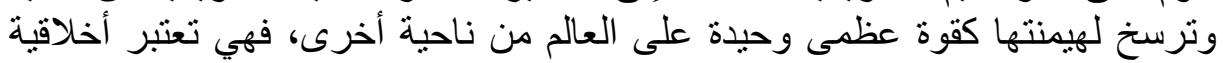

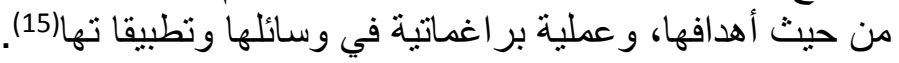

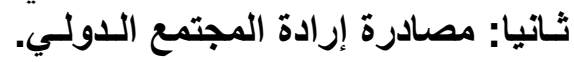

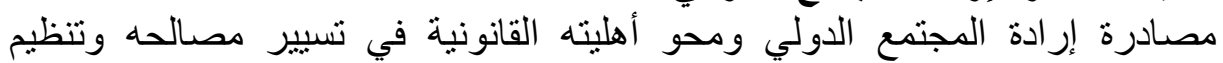

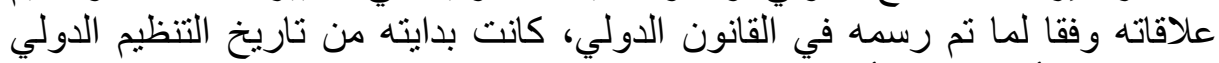

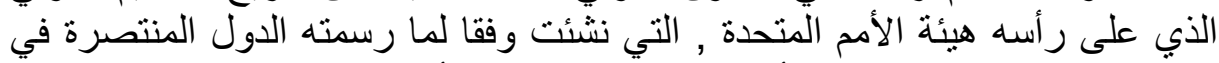

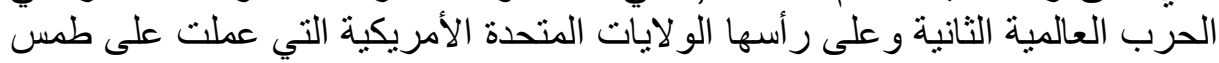

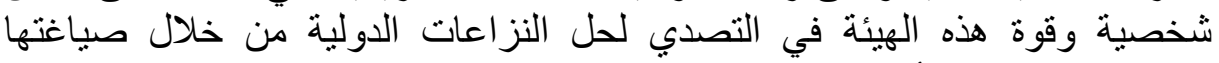

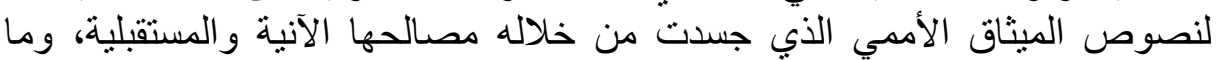

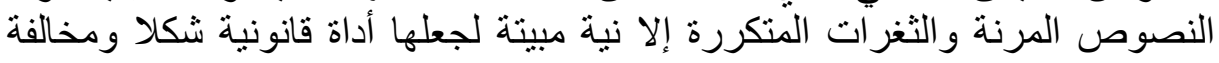

لروح الثرعية الدولية تطبيقا.

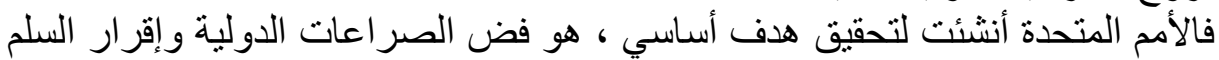

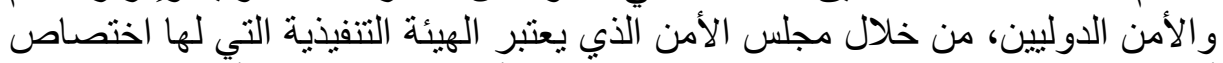

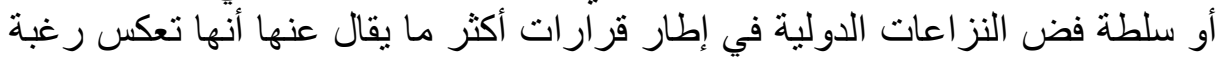

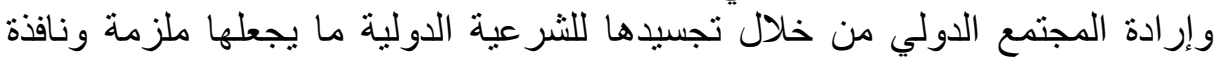
بمجرد صدور ها.

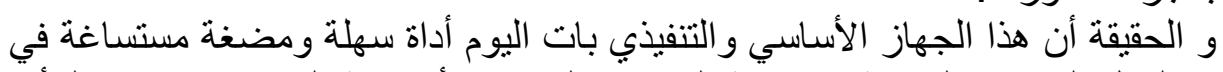

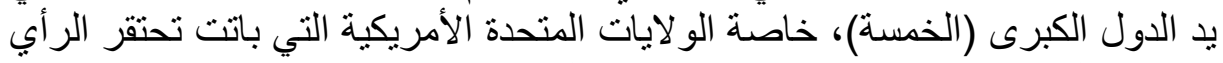

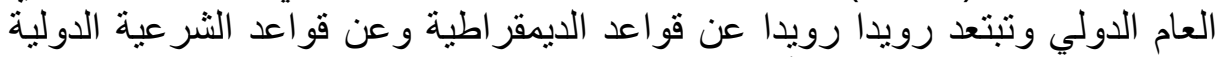

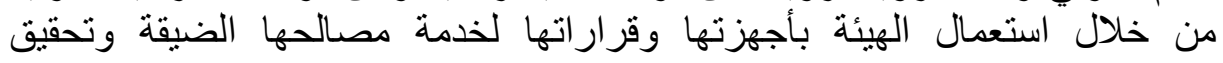


أهدافها، فالو لايات المتحدة الأمريكية مهيمنة على المنظمة الأممية بجميع هياكلها ما يتجلى وينعكس في عدة قضايا دولية.

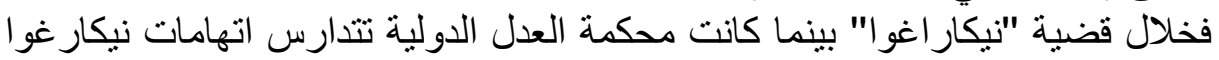

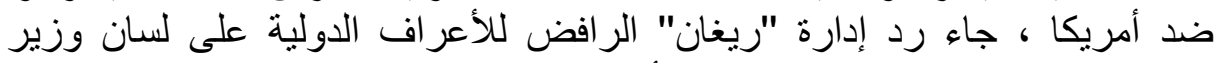

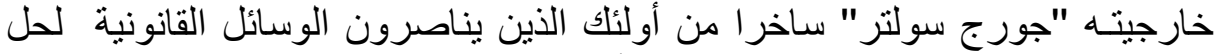

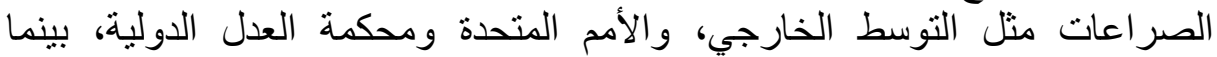

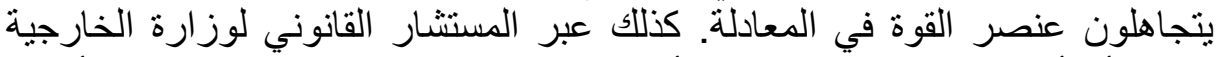

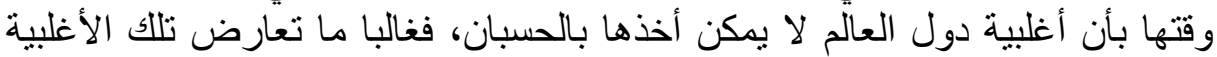

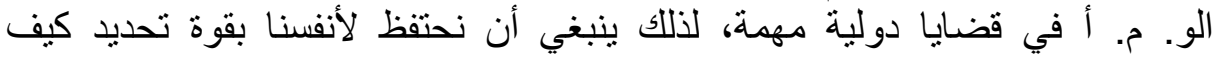

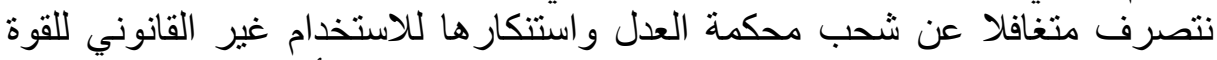

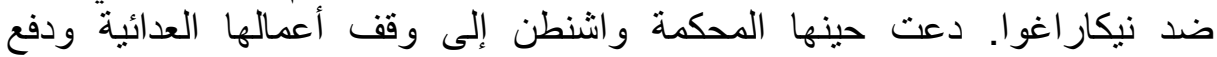

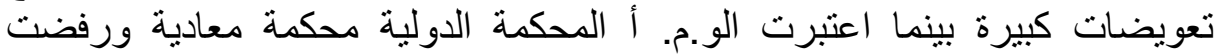

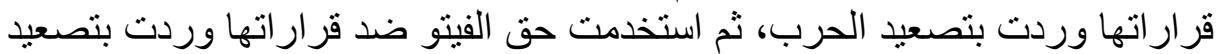

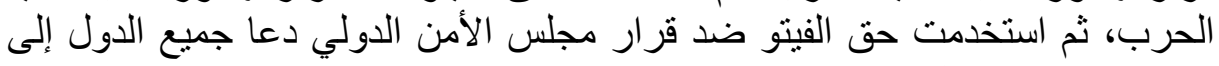

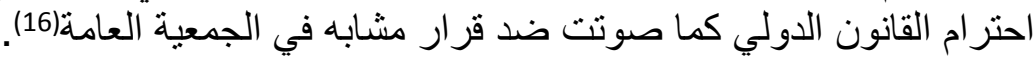

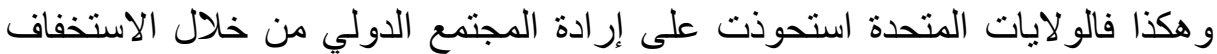

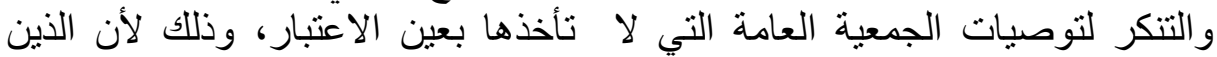

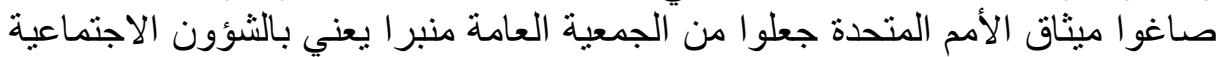
و الإنسانية ومكانا تتنفس فيه الدول الصغرى الصن عن همو مها ومشناكلها.

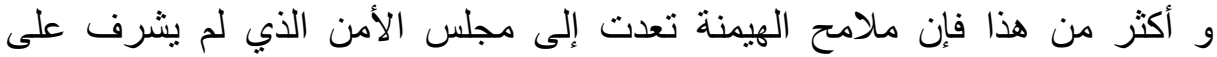

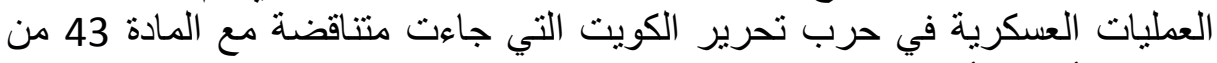

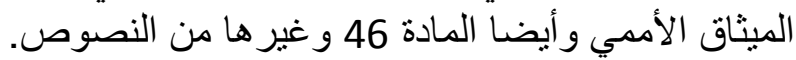

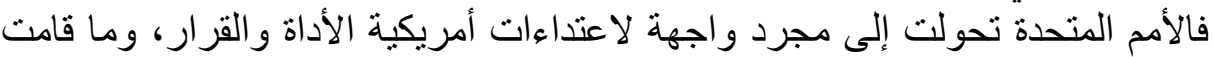

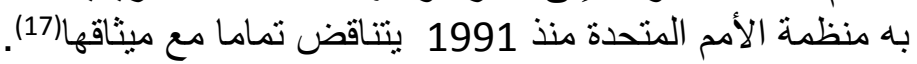
كما تم استغلال أحداث 11 سبتمبر 2001 أسوأ استغلال من خلافل الضرات الضربات الوقائية

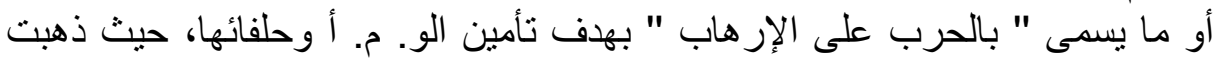

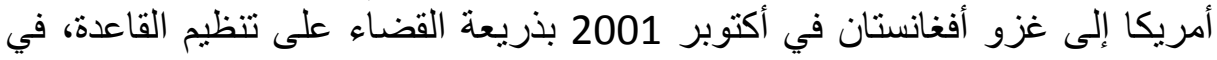

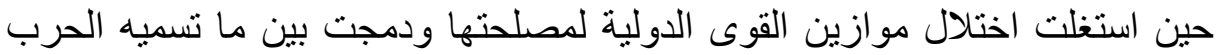

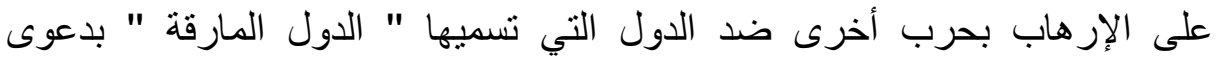

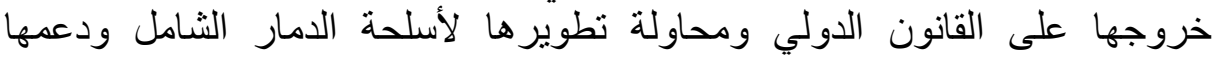
للإزر هاب الذي لم تضع لله تعريف جامع مانع وجعلته مصطلح مفتوح وو اسع المحتوى لاند

فالسياسة الخارجية الأمريكية، استندت على قوتها، في توقيع أند العقوبات التي منها الأنها

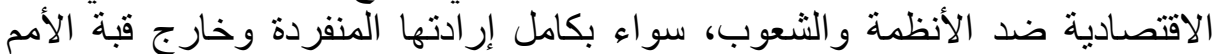

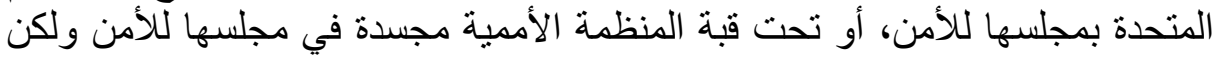

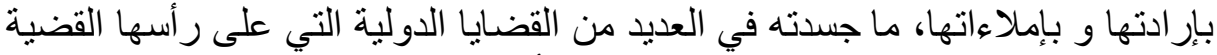

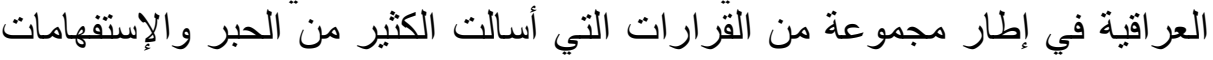

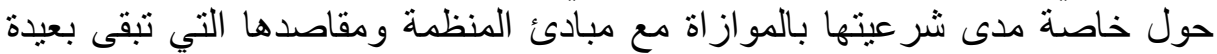
عن قرار اتها وتصرفاتها إزاء القضايا العادلة وغير العادلة المطروحة على الساحة

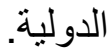
هذا الدور برز كثثيرا في السياسة الخارجية الأمريكية بتصديها للأنظمة الثيوعية وغير الديمقراطية حسب الرؤية الأمريكية.

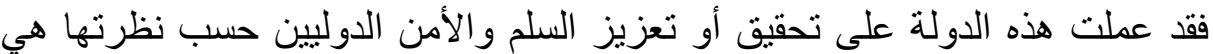

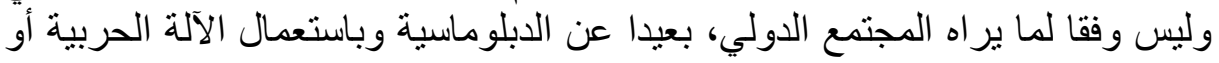




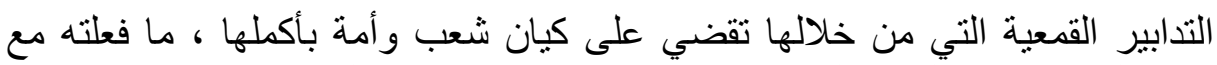

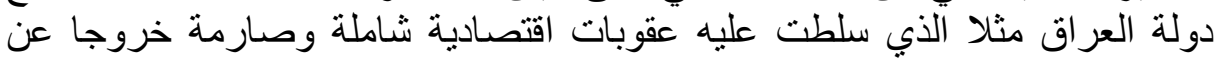

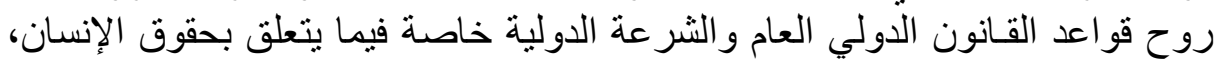

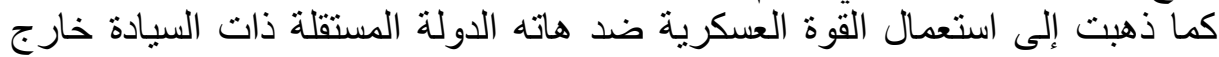

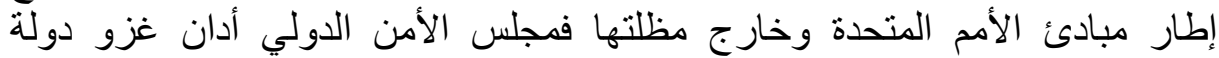

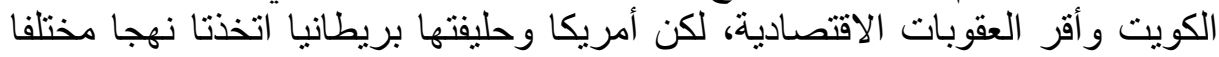

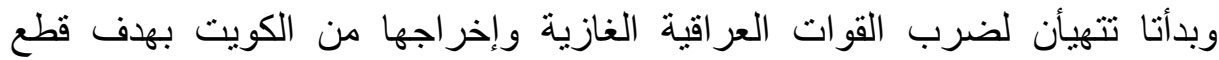
الطريق على الحلول الدبلوماسية(18).

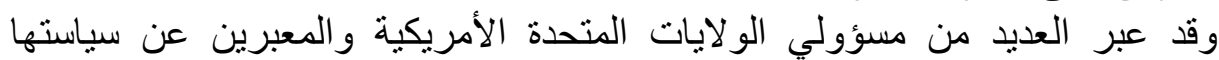

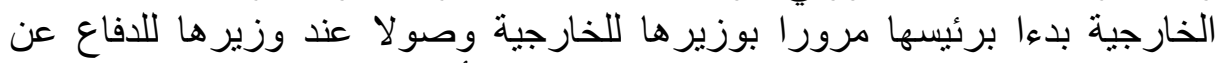

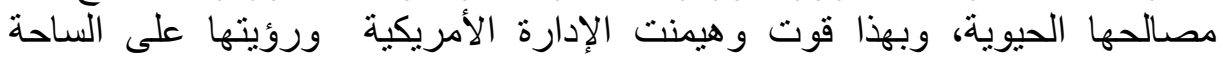
الدولية. ثالثا: السطو على النظام الدولي. أثرت المراحل التي مر بها التئل النظام الدولي وبالأحرى المجتمع الدولي في أساليب

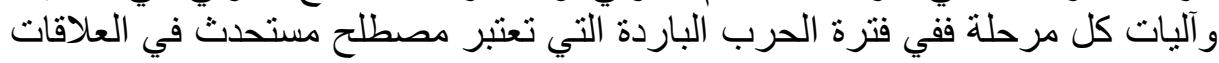

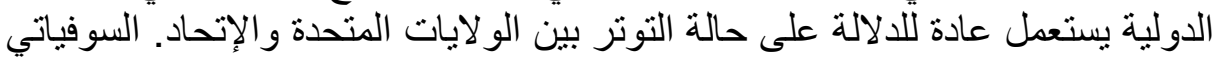

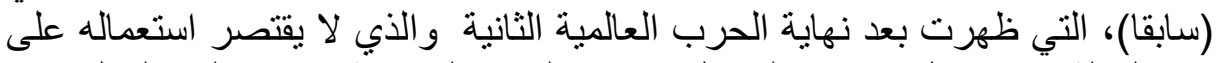

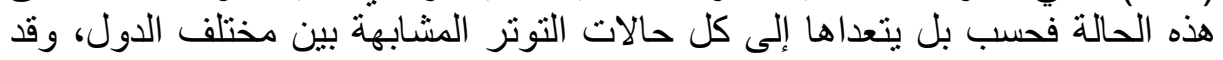

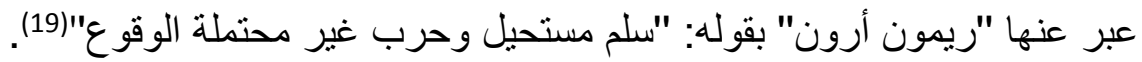

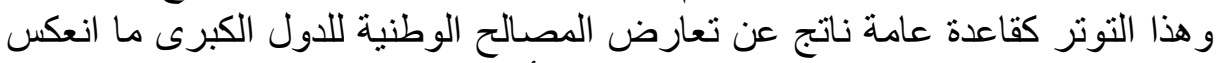

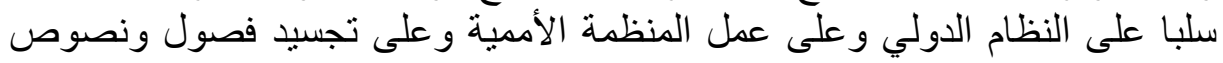
ميثاقها.

ومن ثم فتعارض المصالح أدى إلى نشوب عدة أزمات اجتهدت الو . م. أ أزائها إنها في

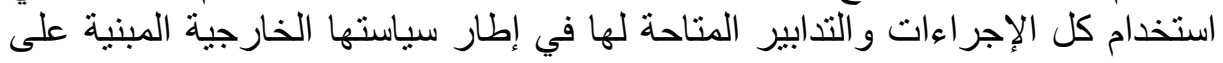

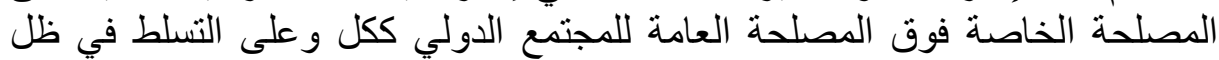

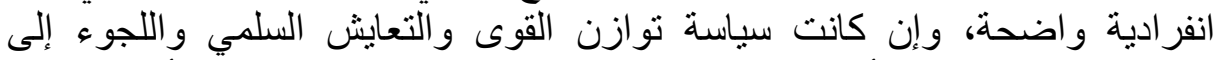

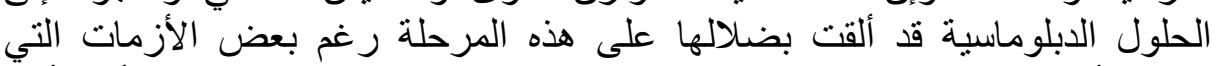

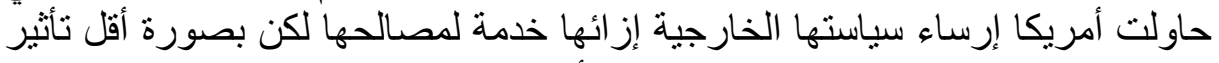

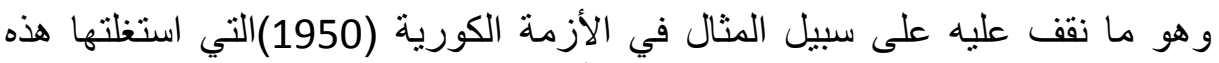

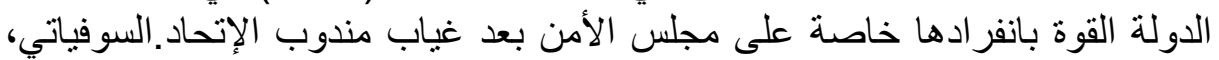

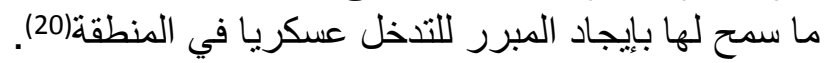

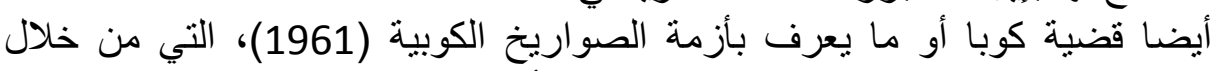

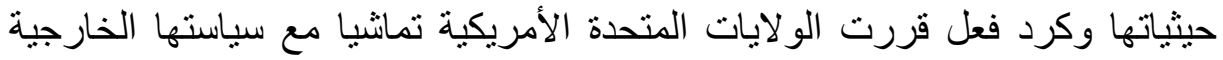

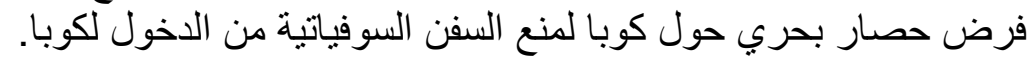

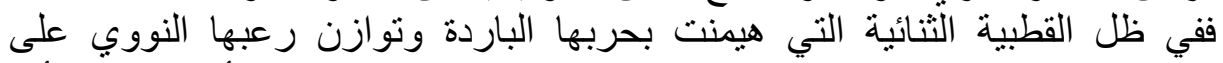

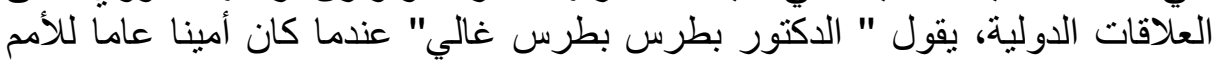

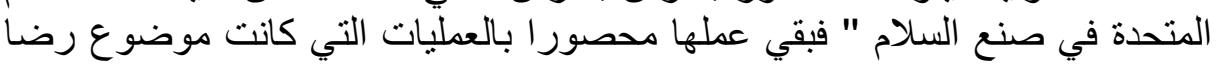
الدولتين العملاقتين لوحدهما(21). أدركت أمريكا خاصة بعد النهيار الإتحاد السوفياتي القطب المباد الموازن في في المعادلة الدولية

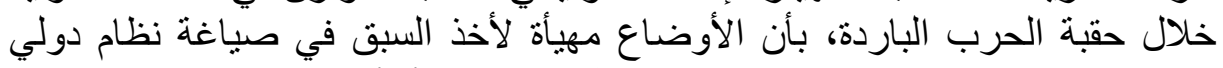
جديد يتو اءم مع منظور ها الإيديولوجي لمرة لمصلحتها القومية(22). 


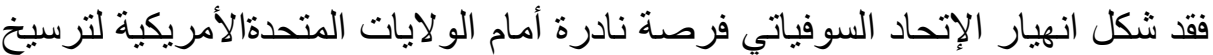

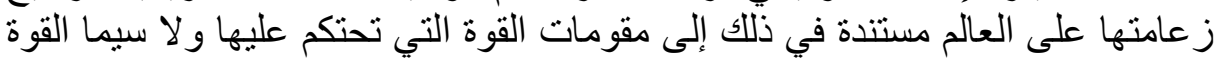

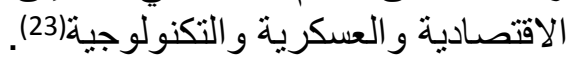

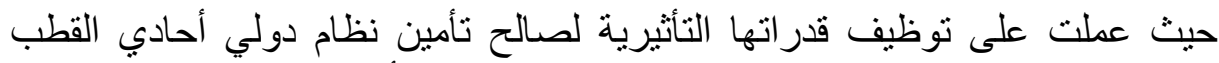

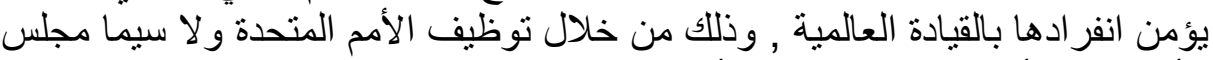

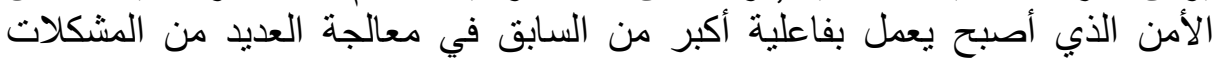

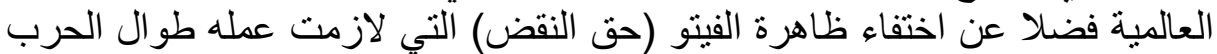

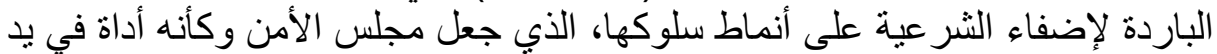

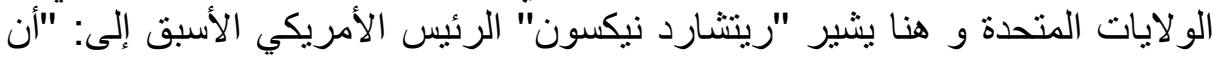

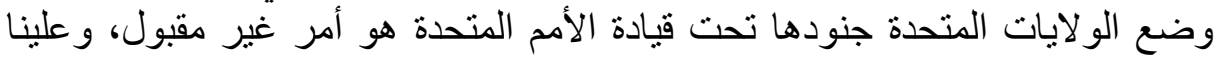

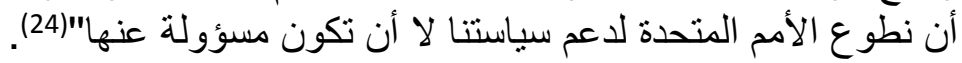

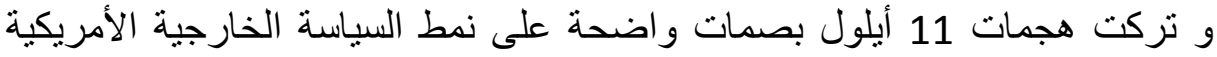

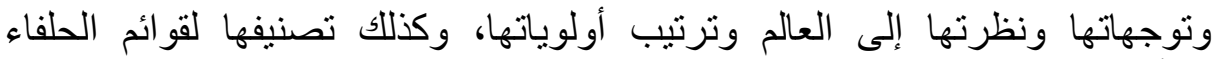
و الأعداء، حيث وفرت هذه العمليات غطاء دبلوماسيا للو لايات المتحدة لتنفيذ سياسات

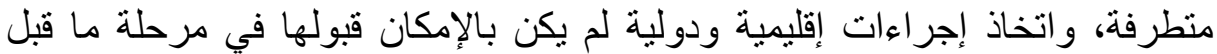

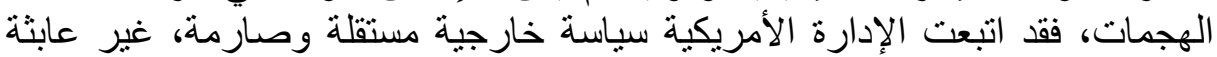

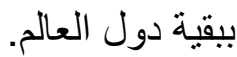

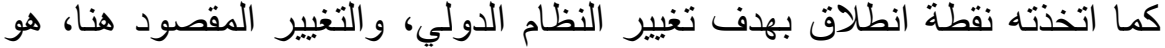

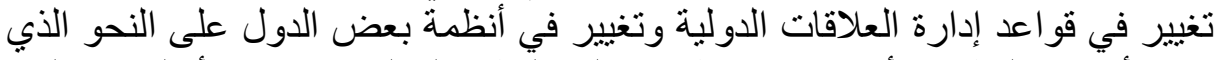

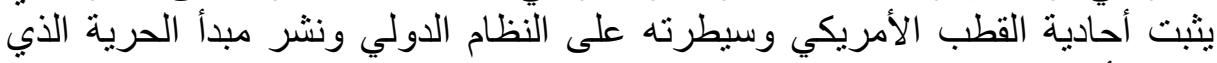

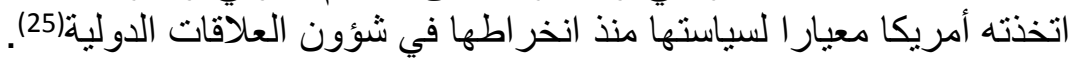

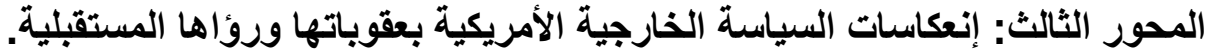

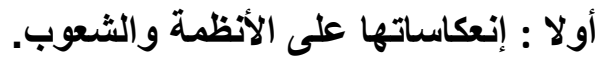

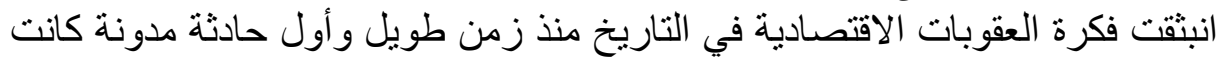

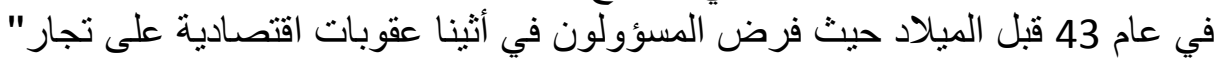

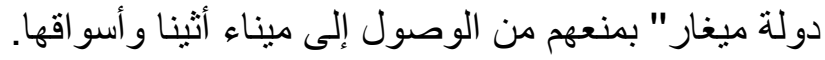

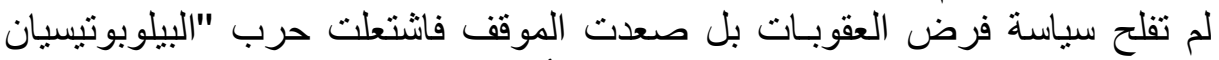
(peloponnsin war)

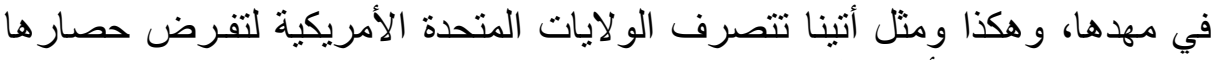

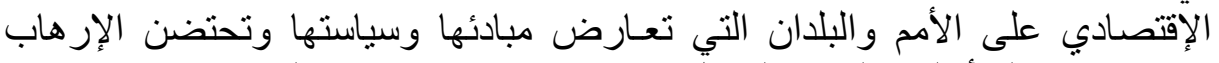

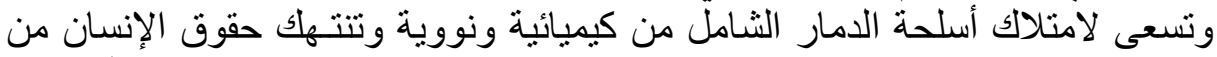

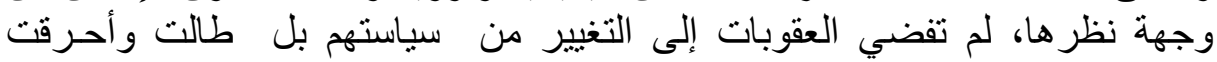

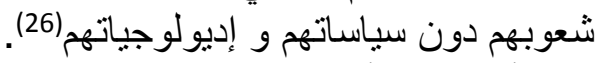

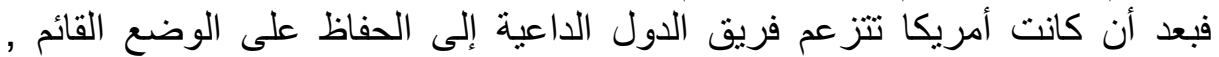

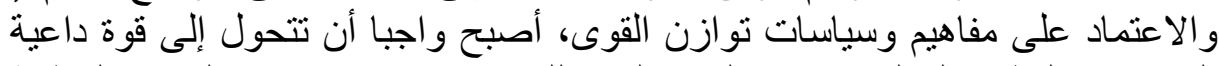

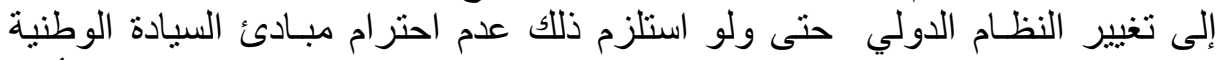

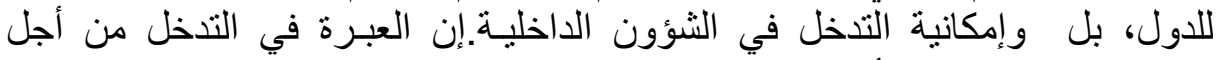

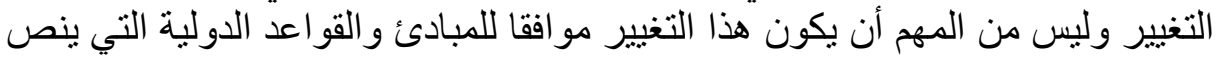

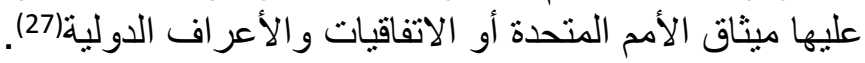

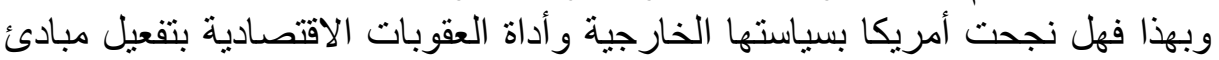

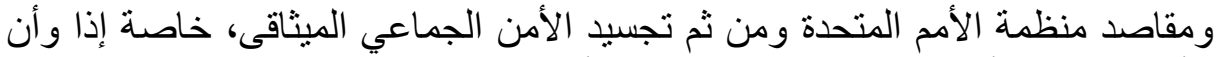

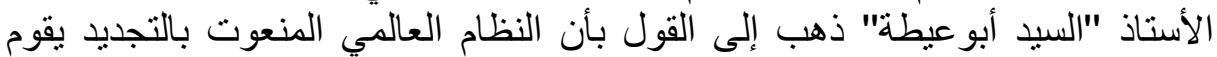

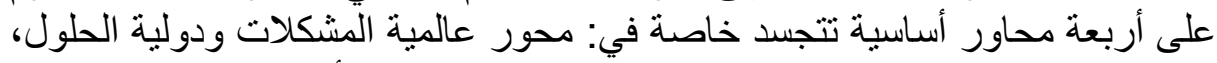
محور الديقراطية واحترام حقوق الإنسان، السلام والأمن الدوليين و والتنمية 
الدولية؟(28)، فالو لايات المتحدة نجحت بسياستها الخارجيـة وعقوباتها الاقتصادية على ذإنى

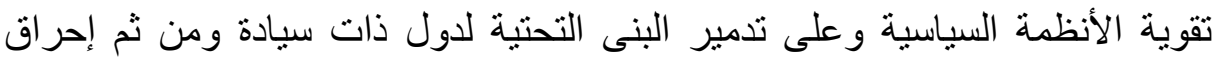

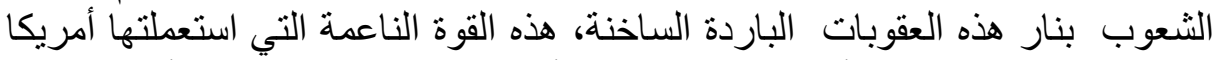

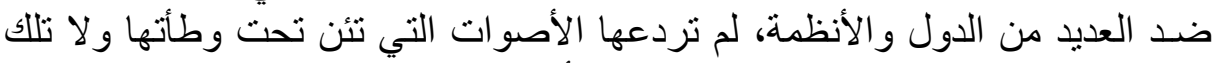

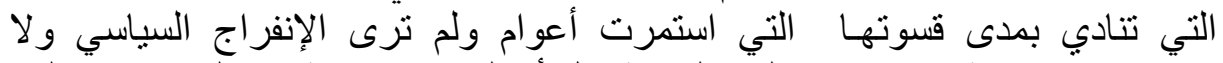

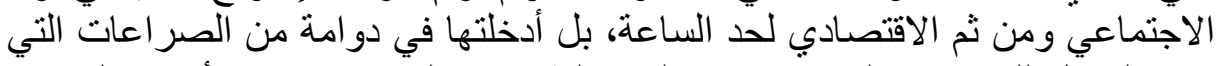

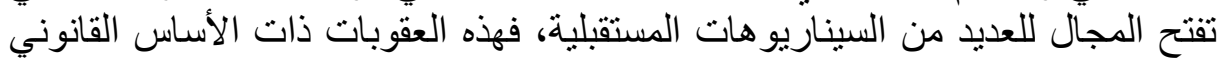

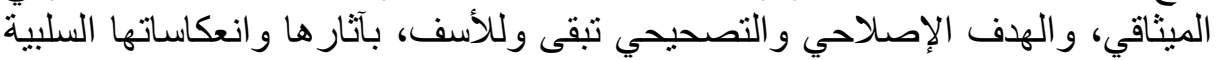

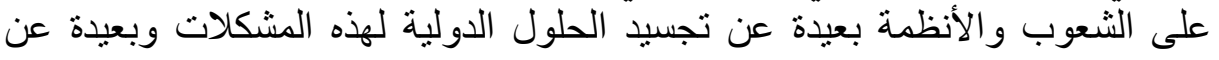

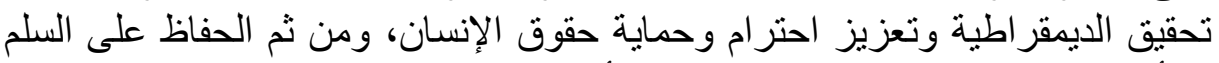

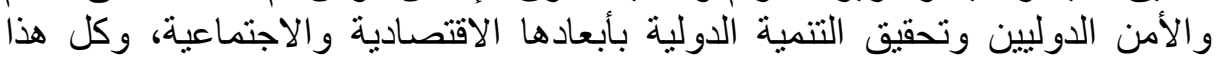

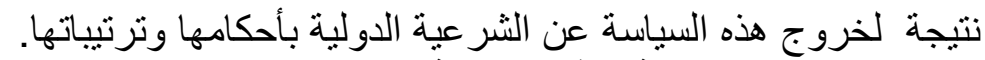

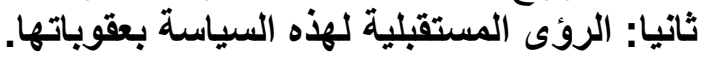

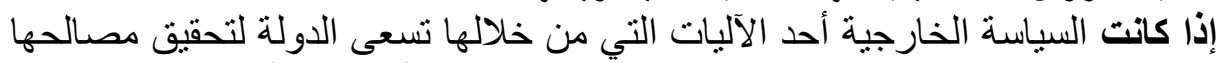

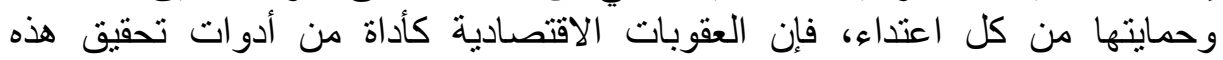

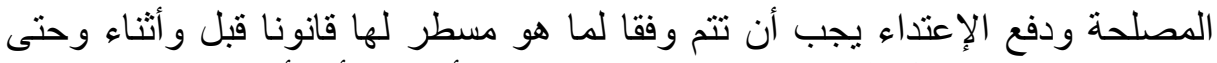

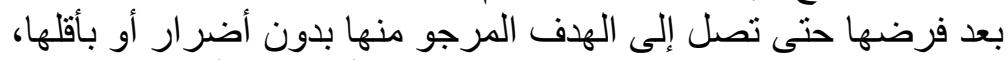

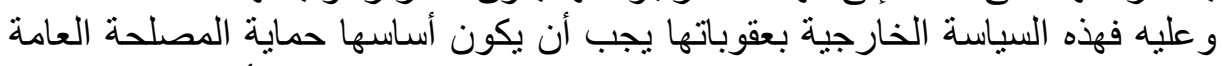

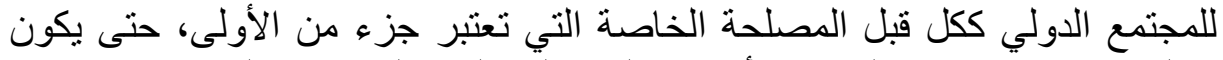

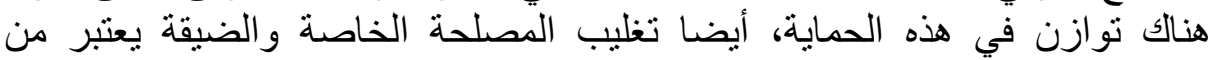

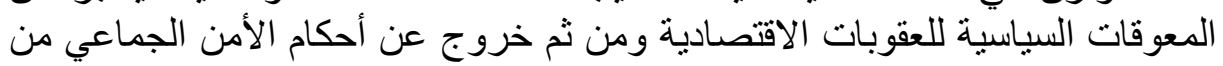

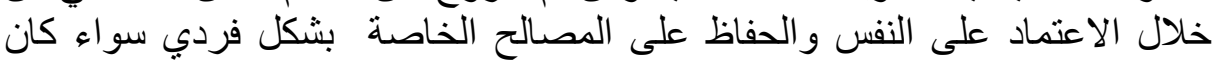

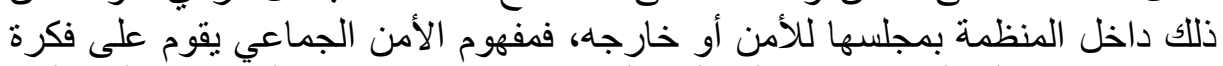

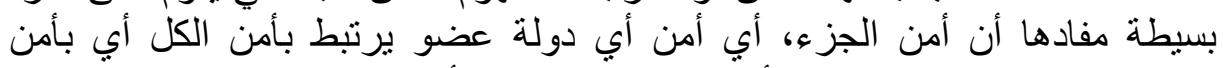

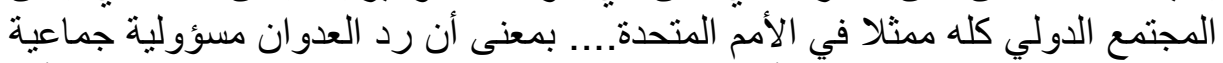

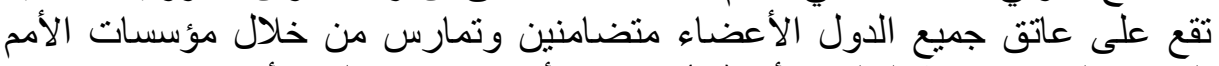

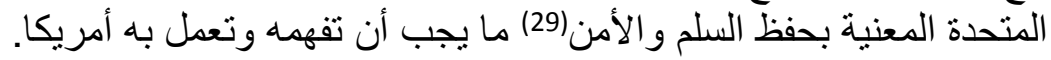

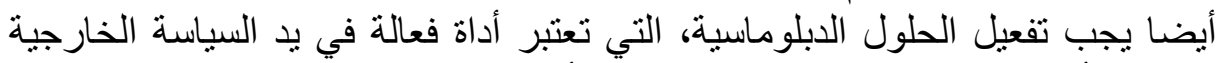

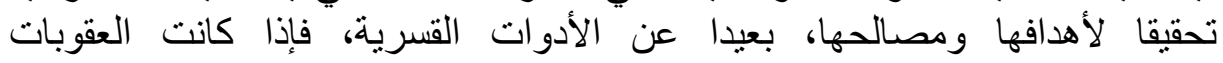

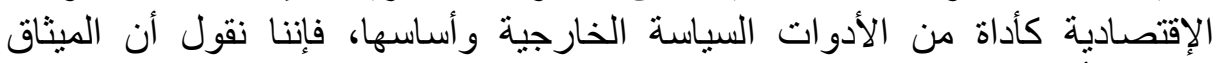

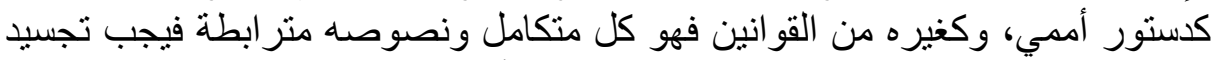

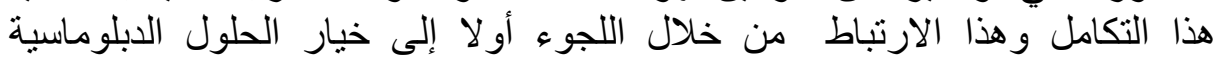

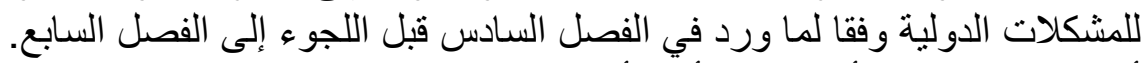

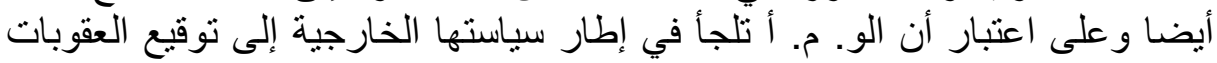

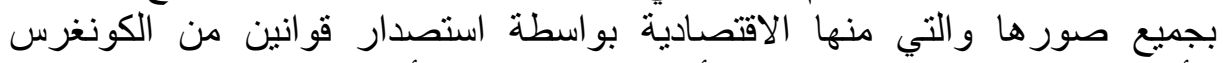

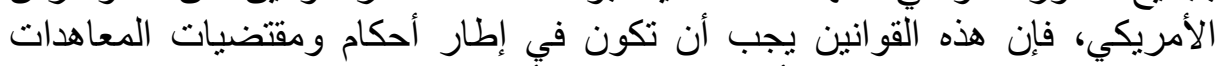

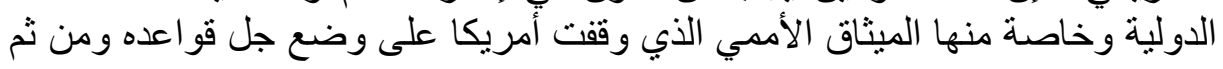

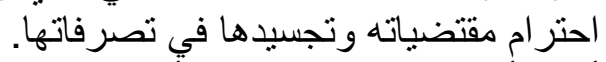

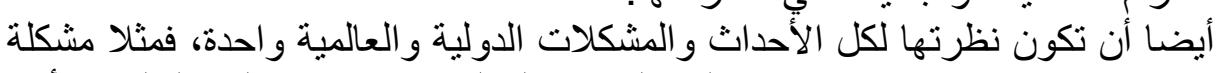

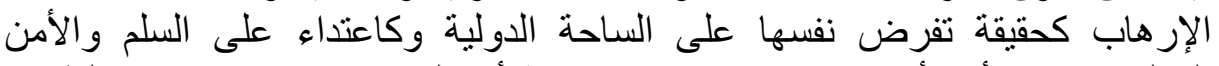

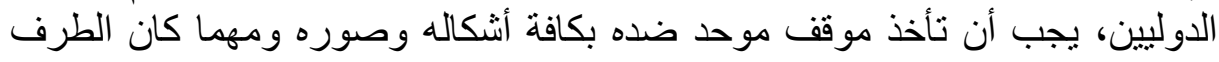

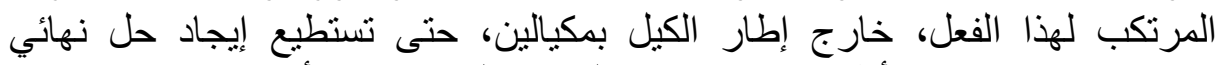
ويضمن حقوق جميع الأطر اف دون انحياز لوارئ لوالحد على حساب الأخر. 
ـ أيضا الانفرادية في اتخاذ القرار داخل أو خارج المنظمة الأممية مجسدة في

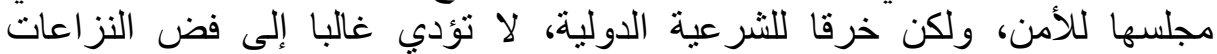

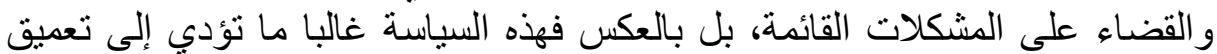

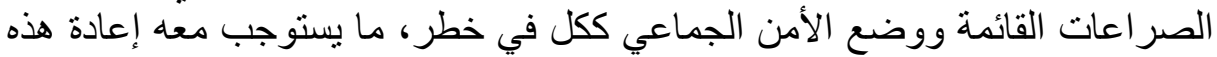

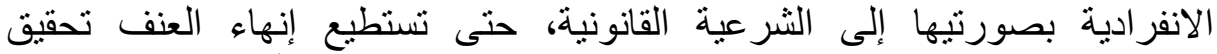
الديمقراطية، تعزيز حماية حقوق الإنسان الحفاظ على السلم والأمن وتحقية الإنيق التنمية الدولية المستدامة بأبعاد ها. ـ تفعيل تدابير الأمن الجماعي وإرجاعة إنهاع منظومة العقوبات الاقتصادية بأهدافها الثر عية

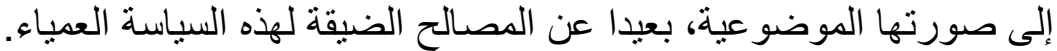

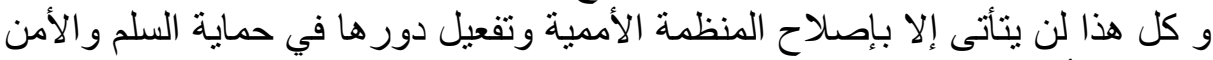

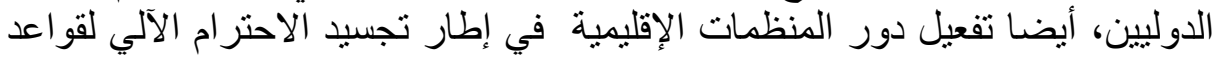
القانون الدولي بفرو عاه ومكوناته.

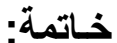

السياسة الخارجية تعتبر أداة من أدوات رسم العلاقات الدولية ومن ثم تحقيق المصالح

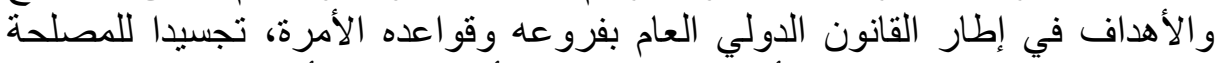

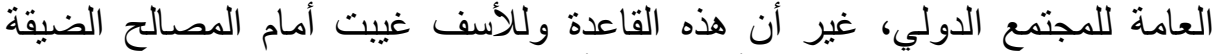

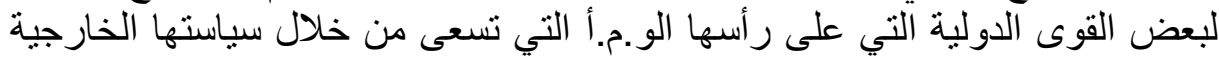

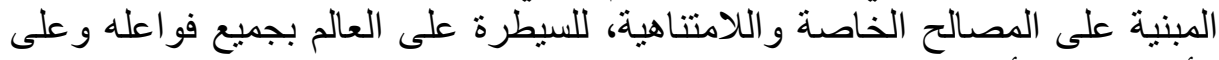
رأسهم هيئة الأمح المتحدة.

هذه السياسة القديمة الجديدة المبنية صوريا على مبادئ قارة دوليا، انطلاقا من والإن

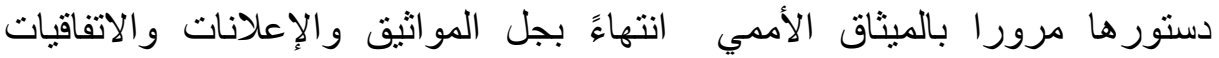

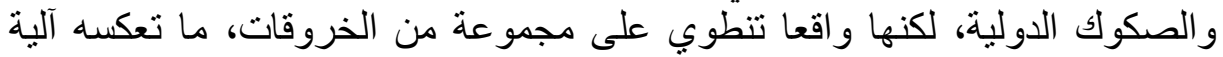

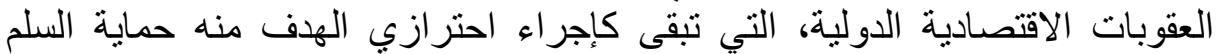

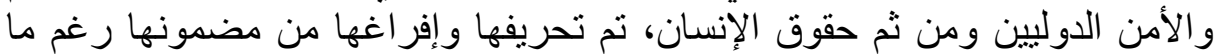

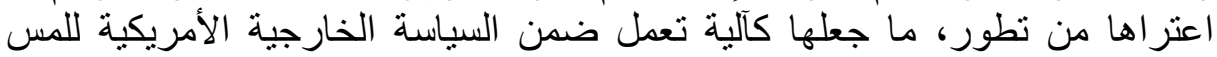

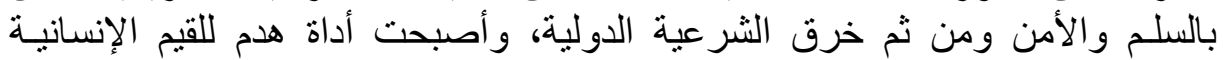

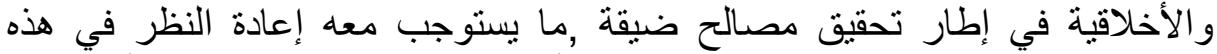

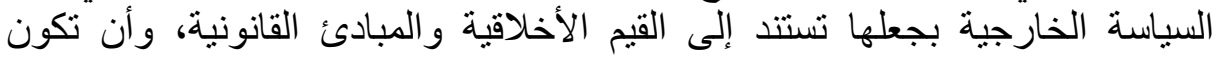

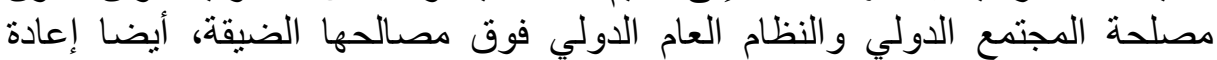

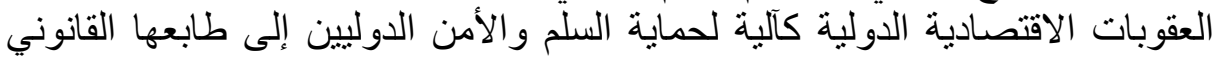

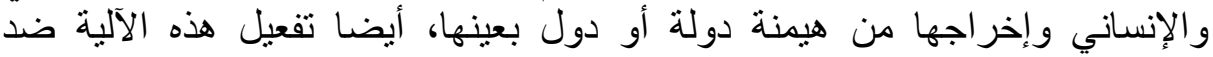

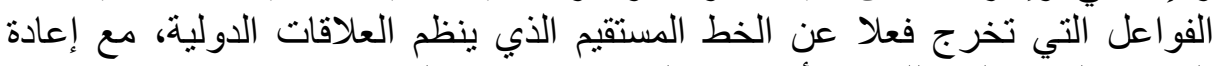
الروح و الهبة والقوة للهيئة الأممية بجعلها شخصية مستقلة بهيئاتها وبقر ارتها.

(1)-Charles philippe david et autres, la politique étrangère des états unis,

fondements, acteurs, formulation, 2eme edition, Paris, Pressès, de sciences po, 2008, P16.

(2)-رياض حمدوش، تأثير السياسة الخارجية الأمريكية على عملية صنع القرار في الاتحاد الأوروبي بعد أحداث 11 سبتمبر 2001، 2012، رسالة مقدمة لنيل درجة الدكتور اهي، كلية الحقوق و العلوم السياسية،

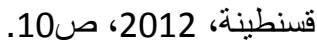

(3)-أ.م.د.مثنى علي المهاوي، إداوي، واقع تدريس السياسة الخارجية في كلية العلوم السياسية، مجلة العلوم

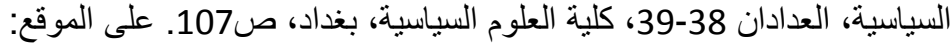

. 04/02/2018http://www.iasj.nediasj?func=funtexta:id=25964

(4)-السيد محمد السيد سليم، تطور السياسة الدولية في القرنين التاسع عشر والعشرين، الطبعة

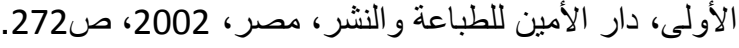

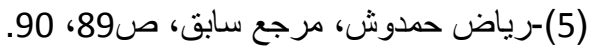


(6)-محمد قجالي، حرب الخليج الثانية بين أحكام القانون الدولي وتداعيات النظام الدولي الجديد،

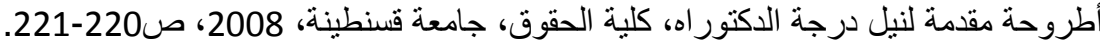

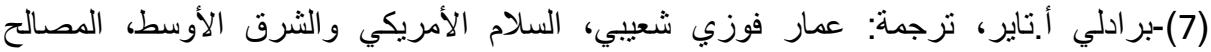

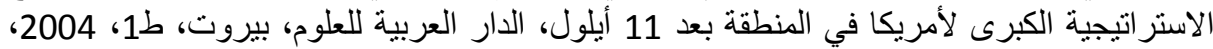

(8)-أمين المشافية، رؤية تحليلية أولية للسياسة الخارجية الأمريكية في عهر ترامب، جريدة الدستور،

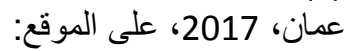

26/01/2018http://www.addvstoun.com/artic/is/62 (9)-محيي الدين قاسم، الدولية المارقة، الرؤية الأمريكية للعالم بعد أحداث سبتمبر، مركز الحضارة

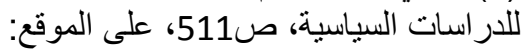
. 04/02/2018.www.hasaracenter.com/index.php?option=com (10)-محيي الدين قاسم، مرجع سابق، ص511. (11)-Affred dezayas, Les sanctions unilatérales violent les accords internationaux.

www.voltairenet.org/article187340.htm.2015. 24/12/2017.

(12)-السيد أبو عيطة، الجزاءات الدولية بين النظرية والتطبيق، مؤسسة الثقافة الجامعية، الإسكندرية, www.ummto.dz/imb/pdf. 05/01/2018.

(13)-قاسم أبودست، سياسة العقوبات الاقتصادية الدولية ونتائج النطبيق في الحالة الإيرانية، مجلة

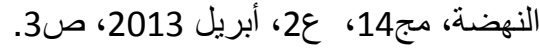

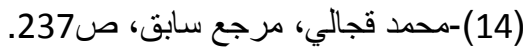

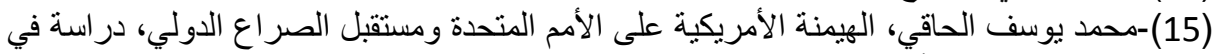

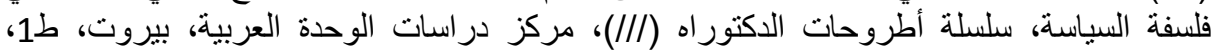

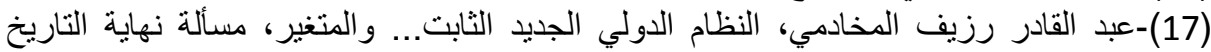

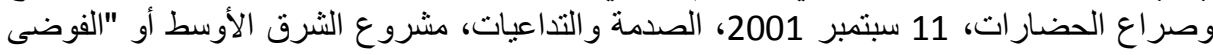

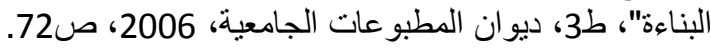

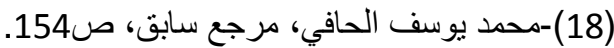

(193)-ز ايد عبيد الله مصباح، السياسة الدولية بين النظرية والتطبيق، دار الرواد، لبنان، ط1، 2002، ص353. (19)

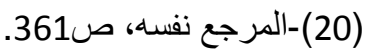

(21)-باسل محسن مهنا، الرؤية الأمريكية للأمم المتحدة 2001، مجلة دراسات دولية، بغداد،441، ص126

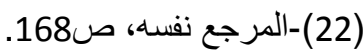

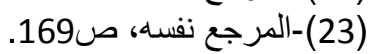

(24)-سليم كاطع علي، مقومات القوة الأمريكية وأثرها في النظام الدولي، مجلة دراسات دولية،

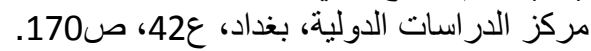
(25)-خليل حسين، النظام العالمي الجديد والمتغيرات الدئ، الدولية، دار المنهل اللبناني، بيروت، ط1،

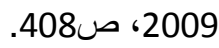
(26)-فروقة جانبي، العراق بين فكي العقوبات وشرارة الضربة العسكرية، جريدة الجزيرة،

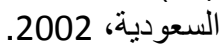
www.al.jazirah.com/2002/2002080/ar3.htm. 04/02/2018.

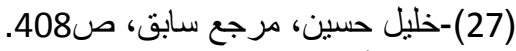
(28)-(28) (29)-حسن نافعة، تأملات في طبيعة الأزمة الراهنة بلنة للأمن الجماعي، ورقة مقدمة في مؤتمر ولتون بارك، حول الأمن المشترك وبناء الثقة، المعهد السويدي، الإسكندرية، 2005. www.fichier_pd.fr/2014/03/03/fochiersans_nom_2. 24/01/2018. 